\title{
EL MOVIMIENTO \\ DE LA POBLACION EXTREMEÑA DURANTE EL ANTIGUO REGIMEN*
}

\author{
ENRIQUE LLOPIS AGELAN \\ Universidad Complutense \\ MIGUEL A. MELON JIMENEZ \\ MIGUEL RODRIGUEZ CANCHO \\ ALFONSO RODRIGUEZ GRAJERA \\ FRANCISCO ZARANDIETA ARENAS \\ Universidad de Extremadura
}

Estar en condiciones de poder presentar un panorama general de la Extremadura moderna exige, entre otras cuestiones prioritarias, reconstruir las principales macromagnitudes económicas '. Sin embargo, los estudios de la producción agrícola y pecuaria, de la renta de la tierra y de los precios, indispensables en las investigaciones sobre el Antiguo Régimen, presentan especiales dificultades en nuestra región, debido al modo habitual de explotar los derechos decimales ', a la compleja realidad territorial - heterogénea y diversa ${ }^{3}$-, a las destrucciones de partes sustantivas de importantes archivos ${ }^{4}$ y a la práctica inexistencia de determinados tipos de fuentes ${ }^{5}$. Se requerirán, por consiguiente, años y un gran esfuerzo investigador antes de estar en condiciones de ofrecer una información serial de las principales variables económicas, tan abundante y fiable como de la que ya se dispone para algunas regiones españolas.

* Queremos expresar nuestro agradecimiento a J. Nadal, quien puso a nuestra entera disposición todas las series de localidades extremeñas que obraban en su poder. En este trabajo se ha utilizado la de Villar del Pedroso. Del mismo modo, nuestra labor se ha visto muy facilitada porque $M$. Fernández-Daza nos permitió el libre acceso a su rico archivo de microfilms.

' Partimos del reconocimiento de que la historia de Extremadura presenta un notorio retraso con relación a la de otras regiones españolas.

: El arrendamiento parece prevalecer en las diócesis de la región. Pese a los grandes esfuerzos desplegados por M. A. Melón Jiménez y A. Rodríguez Grajera, las series decjmales disponibles son insuficientes para establecer una síntesis de la evolución de la producción agraria en la Alta Extremadura durante los siglos xVII y xviII. Véanse A. Rodríguez Grajera (1987), pp. 227-263; M. A. Melón (1989), pp. 75-106.

${ }^{3}$ A. Rodríguez Sánchez (1985), pp. 453-475.

- Por ejemplo, en el Archivo Diocesano de Plasencia y en el Archivo del Monasterio de Guadalupe. Además, en los archivos parroquiales se han conservado muy pocos libros de tazmías y de fábrica.

"La presencia de los monacales en Extremadura ha sido mínima, por lo cual los libros de caja, cuentas o arrendamientos de dichas instituciones no han podido servir de base para el estudio de la renta de la tierra en nuestra región. $\mathrm{Ha}$ sido necesario recurrir a los protocolos notariales, lo que ha entrañado un gran esfuerzo y enormes dificultades para seguir la evolución en el tiempo de los arrendamientos de distintas parcelas de labor o dehesas. Tampoco los archivos nobiliarios han dado demasiado fruto hasta el momento. 
Por el contrario, sí estaba a nuestro alcance, en un período de tiempo relativamente breve, conocer el movimiento de la población extremeña en la época moderna. Nos ha parecido, pues, que este trabajo, además de su posible aportación a la demografía histórica, podría resultar de utilidad a la hora de establecer un plan general de investigación sobre la historia económica y social de la Extremadura moderna ${ }^{\circ}$. Hemos podido apoyarnos en bastantes estudios sobre la población de nuestra región en el Antiguo Régimen ${ }^{7}$, aun cuando aquéllos no llegan a abarcar ni todo el período ni, mucho menos, todo el territorio extremeño ${ }^{8}$. Es decir, los trabajos ya realizados, pese a sernos de gran ayuda, no permiten establecer dicha trayectoria demográfica; sin embargo, resultan imprescindibles para abordar cualquier labor sistematizadora.

\section{I.- El método}

Como es bien conocido, entre 1591 y 1752 no se dispone de ningún recuento fiable de población para el conjunto de Extremadura ${ }^{9}$. Resulta, por tanto, inexcusable la explotación de los libros sacramentales para estudiar el movimiento de la población extremeña durante el Antiguo Régimen. Siguiendo la sugerencia de J. Nadal ${ }^{10}$, vamos a intentar alcanzar dicho objetivo a través del examen de la natalidad en una muestra representativa de localidades extremeñas.

Dejando a un lado la crítica de las fuentes sacramentales, tema al que se han dedicado numerosas páginas y sobre el que existe un elevado grado de acuerdo en los aspectos básicos, la primera objeción a priori al método empleado radica en las muy probables variaciones temporales de la tasa de natalidad: el nivel de los bautismos " medirá tanto más fidedignamente el movimiento de la población cuanto menores hayan sido las oscilaciones de la

- El comportamiento demográfico, como se ha repetido insistentemente, constituye una importante vía de acercamiento a la evolución económica y social; además, el escaso conocimiento de la trayectoria del resto de macromagnitudes, sobre todo en lo que concierne al territorio pacense, le otorga una especial relevancia.

' Un estado de la cuestión y una relación bibliográfica prácticamente exhaustiva de esos trabajos puede hallarse en A. Rodríguez Sánchez (1988), pp. 285.290 y 492-496. La demografía ha concentrado buena parte de los esfuerzos investigadores del Area de Historia Moderna de la Universidad de Extremadura.

- El desequilibrio entre las investigaciones sobre las provincias de Cáceres y Badajoz, mucho más numerosas en la primera, también afectaba al terreno demográfico.

- El Vecindario de Campoflorido resulta inutilizable para el conjunto de Extremadura, entre otras razones porque no llegó a confeccionarse en un número importante de núcleos de la región. Véase M. A. Melón (1989), pp. 30.31.

10 J. Nadal (1988), pp. 39-42.

" Para medir dicho nivel utilizaremos medias móviles centradas de nueve años. 
referida tasa. Sabemos que ésta, aun cuando se mantuvo relativamente alta durante toda la época moderna, registró incrementos y descensos significativos. Sin embargo, consideramos que ese problema no entraña la descalificación de la metodología utilizada: en primer lugar, porque disponemos de información sobre el comportamiento del cociente entre bautizados y nupcias ${ }^{12}$ en varias localidades extremeñas durante los siglos XviI y xviII ${ }^{13}$, lo que nos permite conocer el signo y estimar con un cierto grado de fiabilidad la intensidad de las variaciones de la tasa de natalidad y, por ende, corregir los índices de población en consonancia con dicho movimiento ${ }^{14}$; en segundo lugar, porque las fluctuaciones de la tasa de natalidad suelen ser casi siempre inversamente proporcionales a la dimensión de la muestra que se esté examinando ${ }^{15}$. En suma, aunque las cifras que presentamos deban ser consideradas como meras estimaciones aproximativas, no hay duda de que el método empleado constituye la única vía posible, y mínimamente fiable, para seguir el movimiento de la población regional en la España moderna ${ }^{16}$.

La muestra sobre la que va a sustentarse nuestro trabajo está integrada por 37 localidades ${ }^{17}, 18$ pacenses y 19 cacereñas, que concentraban el 13,87 por 100 de la superficie ${ }^{18}$ y el 17,47 por 100 de la población extremeña en $1787^{19}$. Hemos intentado que la muestra fuera lo más amplia posible, pero tal objetivo lo hemos sometido a dos condiciones restrictivas:

${ }^{12}$ Dicho cociente es generalmente considerado como un indicador aceptable de la fecundidad.

${ }^{13}$ A. Rodriguez Grajera (1987), p. 216; M. A. Melón (1989), p. 52.

14 Una vez conocidos los cambios en la tasa de natalidad, los índices de población basados en las cifras bautismales son corregidos mediante reglas de tres elementales.

"En este caso vamos a emplear una muestra de 37 localidades que albergaban una población de 74.009 habitantes en 1787.

in Es cierto que en algunos archivos municipales se conservan numerosos padrones y vecindarios, pero ese fenómeno está circunscrito a un pequeño porcentaje de núcleos, por lo que este tipo de fuentes no permite la realización de estudios regionales o nacionales.

1 La lista y características de dichos núcleos aparecen en el cuadro A.1 del Epéndice estadístico: número de vecinos en 1591; número de haibtantes en 1787; extensión; densidad de población en 1787; topografía (llano o montaña); tamaño (grande, mediano o pequeño): jurisdicción a la que pertenecía en 1787; zona de la región (Oeste, Centro y Este).

in Debemos aclarar que el marco espacial de nuestro trabajo está integrado por el territorio atribuido a las provincias de Cáceres y Badajoz por el Real Decreto de 30 de noviembre de 1833, territorio que coincide con la actual Comunidad Autónoma de Extremadura.

19 En 1787 la población del territorio de Extremadura no ascendía a 417.202 habitantes, tal y como aparece en la publicación del Censo de Floridablanca realizada recientemente por el INE, sino a 423.492. Tal diferencia obedece a que dicha publicación asigna, por error, a Jerez de los Caballeros una población de sólo 1.081 almas, cuando ésta se elevaba, según la documentación primaria del referido censo, a 7.371 (BRAH, Censo de Floridablanca, 9.30-2, leg. 6202). Faltan los datos de Villar del Rey, perdidos, y de Olivenza y Táliga, portuguesas hasta 1801. Por otra parte, si utilizamos las hojas-resúmenes de cada núcleo, y no el total de la provincia, la cifra de población varía. 
1. Unicamente hemos incluido aquellas localidades en que los registros bautismales estuviesen completos o presentasen unas lagunas temporales mínimas ${ }^{20}$ en el período $1550 / 1570-1840^{21}$.

2. Se ha procurado que las características de la muestra, especialmente en lo que respecta a condiciones geográficas y distribución de los núcleos según su tamaño, se asemejen lo más posible a las del conjunto regional. Es decir, intentamos que constituyera una reproducción, en otra escala espacial, de la geografía y del poblamiento de la Extremadura del Antiguo Régimen ${ }^{22}$.

Pese al esfuerzo desplegado, somos conscientes de que la muestra de 37 localidades adolece de algunos defectos. El número de núcleos nos parece suficiente, pero no se ha conseguido una equilibrada representación de todas las comarcas extremeñas. En la provincia de Cáceres, la Tierra de Trujillo, los Riberos del Tajo y la comarca placentina están insuficientemente representadas. En cuanto a Badajoz, el desequilibrio entre el Norte y el resto de la provincia resulta patente, siendo especialmente llamativa la ausencia de núcleos de la Siberia extremeña ${ }^{23}$. Salvo en el caso de los Riberos del Tajo ${ }^{24}$, las fuentes disponibles no permiten mejorar de modo sustancial la representatividad geográfica de la muestra ${ }^{25}$. En cualquier caso, ésta reproduce bastante aceptablemente la diversidad de los espacios de la región.

* Para subsanar las lagunas de menos de un año nos hemos basado en las distribu. ciones mensuales de los bautismos en Almendralejo para los núcleos de la provincia de Badajoz, mientras que para la provincia de Cáceres se han estimado en relación a la media de los tres años anteriores en cada uno de los núcleos. Cuando la falta de información era de uno o varios años, la estimación del número de bautizados se ha realizado teniendo en cuenta el nivel de la natalidad en la misma localidad en los años inmediatamente anteriores y posteriores, y el comportamiento de aquélla en el núcleo más próximo para el que dispusiésemos de todos los registros de bautizados en el período en cuestión.

"De haber podido formar un número minimamente representativo de series para la primera mitad del siglo xvI, habriamos extendido nuestra investigación a dicho período.

22 También hubiera sido conveniente buscar la representatividad económica de los núcleos. Sin embargo, no disponemos de suficiente información para aplicar de un modo riguroso este criterio. Por otro lado, es indudable que las características geográficas de las localidades ejercian una influencia notable sobre sus respectivas economías en la época moderna. Por cllo, la representatividad cconómica no está ausente de la muestra, aunque se haya logrado a través de un procedimiento indirecto.

${ }^{23}$ Comarca situada al Noreste de la provincia. La documentación conservada en sus archivos parroquiales no permite la inclusión de ningún núcleo en nuestra muestra.

${ }^{24}$ Desde el punto de vista eclesiástico, muchas de las localidades de esa comarca pertenecían al Arzobispado de Toledo, cuyos archivos parroquiales no se encuentran microfilmados en el Centro Cultural Santa Ana de Almendralejo. Al carecer de un conocimiento exhaustivo de la documentación que se conserva en dichos archivos no podemos afirmar que no sea posible subsanar la insuficiente representación de los Riberos del Tajo en nuestra muestra. Esperamos conseguir pronto esa información a fin de añadir, en su caso, alguna localidad de dicha comarca.

${ }^{2}$ Se puede conseguir un mayor equilibrio en la representación de las distintas comarcas, pero a costa de reducir el ímbito temporal del estudio al período 1630/1650-1840. En un futuro próximo nos plantearemos abordar un trabajo de esas características, a fin de contrastar y matizar las conclusiones de la presente investigación. 
Los principales sesgos de la muestra se concentran en el peso demográfico otorgado a los territorios provinciales y en la distribución de los núcleos según su tamaño. De acuerdo con los datos del Vecindario de 1591, la actual provincia de Cáceres albergaba al 50,47 por 100 de la población extremeña. Sin embargo, los 19 núcleos cacereños en esa misma fecha sólo reunían el 41,91 por 100 de los vecinos de las 37 localidades de la muestra regional ${ }^{26}$. En 1787 ese desequilibrio, aunque menos acusado, persistía: 46,29 por 100 frente a 42 por 100 , respectivamente ${ }^{27}$. Se ha intentado corregir este sesgo desfavorable para Cáceres ponderando las variaciones en el número de los bautizados por el distinto peso demográfico relativo que hemos atribuido a cada una de las dos provincias extremeñas en distintos momentos ${ }^{28}$. Aunque la estimación precisa de los porcentajes de la población cacereña y pacense en el conjunto regional plantea arduos problemas ${ }^{29}$, consideramos que el empleo de índices ponderados permite corregir la mayor parte del sesgo que podría ocasionar la sobrerrepresentación de la Baja Extremadura en nuestra muestra.

A nuestro juicio, el mayor defecto del soporte documental cuantitativo del trabajo radica en la infrarrepresentación de los pueblos pequeños. Para efectuar una primera aproximación de carácter instrumental a la distribución de los extremeños de acuerdo con el tamaño de los núcleos en que residían, hemos distinguido tres tipos de localidades: las grandes - de más de 500 vecinos o de 1.900 habitantes-, las medianas -entre 200 y 500 vecinos o entre 760 y 1.900 habitantes-. y las pequeñas - de menos de 200 vecinos o de 760 habitantes-. Veamos de qué modo se repartía la población extremeña y la de los núcleos de la muestra en 1591 y $1787^{30}$.

2t El recuento de 1591 no ofrece información singularizada de la población de Jerez de los Caballeros, proporcionando sólo la suma de los vecinos de dicha ciudad y de sus núcleos anejos, Valle de Santa Ana y Valle de Matamoros. Hemos estimado el vecindario de Jerez de los Caballeros de 1591 suponiendo que la distribución de la población entre la ciudad y sus anejos era idéntica a la de 1787.

${ }_{27}$ En términos relativos, entre 1591 y 1787 el comportamiento demográfico de los núcleos de la muestra cacereña parece ser mejor que el de los núcleos pacenses. Sin embargo, albergamos dudas sobre la fiabilidad, al menos en lo que concierne a nuestra región, de los datos del Vecindario de 1591 y del Censo de Floridablanca, tema al que dedicaremos alguna atención más adelante.

" Mediante la estimación de las tasas de natalidad de las 37 localidades muestreadas hemos intentado contrastar la fiabilidad de los recuentos de 1591 y 1787. Los resultados de estos tests los exponemos en el último epígrafe de este trabajo.

${ }_{20}$ Entre otras razones por la dudosa fiabilidad de los recuentos generales que han de servir de punto de partida para la estimación de los porcentajes en distintos momentos.

${ }_{s 0}$ Como es bien conocido, en el Vecindario de 1591 aparecen, en ocasiones, agregados los vecinos de dos o más núclens. Ello dificulta el estudio del grado de concentración demográfica, lo que en nuestro caso nos ha obligado a distinguir exclusivamente entre localidades grandes y localidades medianas y pequeñas. 


\section{CUADRO 1}

1.A. Distribución de la población según los datos del Vecindario de 1591 (En porcentajes)

\begin{tabular}{|c|c|c|c|c|}
\hline & \multicolumn{2}{|c|}{$\begin{array}{c}\text { DATOS PROVINCIALES } \\
\text { Y REGIONALES }\end{array}$} & \multicolumn{2}{|c|}{$\begin{array}{l}\text { DATOS DE LOS NUCLEOS } \\
\text { DE LA MUESTRA }\end{array}$} \\
\hline . & $\begin{array}{l}\text { Localidades } \\
\text { pequeñas } \\
\text { y medianas }\end{array}$ & $\begin{array}{l}\text { Localidades } \\
\text { grandes }\end{array}$ & $\begin{array}{l}\text { Localidades } \\
\text { pequeñas } \\
\text { y medianas }\end{array}$ & $\begin{array}{l}\text { Localidades } \\
\text { grandes }\end{array}$ \\
\hline $\begin{array}{lllllll}\text { Cáceres } & \ldots & \ldots & \ldots & \ldots & \ldots & \ldots\end{array}$ & 60,45 & 39,54 & 60,49 & 39,50 \\
\hline $\begin{array}{llllll}\text { Badajoz } & \ldots & \ldots & \ldots & \ldots & \ldots\end{array}$ & 41,55 & 58,44 & 24,06 & 75,39 \\
\hline $\begin{array}{lllll}\text { Extremadura } & \ldots & \ldots & \ldots & \ldots\end{array}$ & 51,09 & 48,90 & 39,33 & 60,66 \\
\hline
\end{tabular}

1.B. Distribución de la población según los datos del Censo de Floridablanca (En porcentajes)

\begin{tabular}{|c|c|c|c|c|c|c|}
\hline & \multicolumn{3}{|c|}{$\begin{array}{c}\text { DATOS PROVINCIALES } \\
\text { Y REGIONALES }\end{array}$} & \multicolumn{3}{|c|}{$\begin{array}{c}\text { DATOS DE LOS NUCLEOS } \\
\text { DE LA MUESTRA }\end{array}$} \\
\hline & Pequeñas & Medianas & Grandes & Pequeñas & Medianas & Grandes \\
\hline Cáceres $\ldots \ldots$ & 27,13 & 33,05 & 37,80 & 9,52 & 30,48 & 59,99 \\
\hline Badajoz ... ... & 10,48 & 29,05 & 60,09 & 2,73 & 15,45 & 81,80 \\
\hline Extremadura . & 18,38 & 31,83 & 49,77 & 5,58 & 21,76 & 72,64 \\
\hline
\end{tabular}

Fuentes: Elaboración propia a partir del Censo de Castilla de 1591. Vecindarios (1984) y del Censo de 1787 \&Floridablanca". Tomo II. Comunidades Autónomas de la Submesela Sur (1987).

Como puede apreciarse en el cuadro 1, la muestra presenta un sesgo importante a favor de las localidades grandes ${ }^{31}$. Vamos a intentar paliar dicho inconveniente mediante la aplicación de las oportunas ponderaciones ${ }^{32}$. No obs-

31 En 1787 el número medio de habitantes por núcleo era de 1.094 y de 2.000 en la región y en las 37 localidades de la muestra, respectivamente. En la provincia de Cáceres dichas cifras ascendían a 856 y 1.636 y en la de Badajoz a 1.439 y 2.384 , respectivamente.

${ }^{32}$ Hemos empleado la distribución de 1591 en los indices ponderados de los datos anteriores a 1652, mientras que se ha recurrido a la de 1787 para los del siglo xvIII. También podríamos haber utilizado la del Catastro de la Ensenada, pero consideramos que la ganancia neta sería pequeña. 
tante, el número de núcleos de la muestra de menos de 200 vecinos en 1591 (cuatro de Cáceres y cuatro de Badajoz) nos parece insuficiente para representar adecuadamente el comportamiento de todos los pueblos pequeños de la región. El problema afecta más a Cáceres que a Badajoz: en 1787 las localidades pequeñas concentraban el 27,13 y el 10,84 por 100 de la población de ambas provincias, respectivamente. En cualquier caso, en la muestra parece estar bien representada más del 80 por 100 de la población extremeña, ya que los núcleos pequeños sólo reunían en 1787 al 18,3 por 100 de los habitantes de la región. Además, las fuentes disponibles no facilitan una corrección adecuada del referido desequilibrio, ya que sus archivos parroquiales suelen estar peor conservados. Paliar la sobrerrepresentación de las localidades grandes habría exigido la drástica reducción de la muestra, alternativa que entrañaba, en nuestra opinión, bastantes más perjuicios que ventajas.

En definitiva, la muestra manejada presenta algunos sesgos, siendo especialmente importante el insuficiente peso relativo que tienen los núcleos pequeños, pero consideramos que esa «Extremadura en miniatura» reproduce bastante bien la geografía y el tipo de poblamiento de la región y, sobre todo, los libros de bautismos disponibles no parecen permitir una notable mejora de la muestra. En otras palabras, no estamos muy lejos del óptimo posible ${ }^{33}$.

\section{La trayectoria de la natalidad en la región}

En el cuadro A.2 del Apéndice estadístico hemos recogido las series de bautizados regionales, una de 20 y otra de 37 localidades ${ }^{34}$, y las provinciales, la de Cáceres de 19 núcleos y la de Badajoz de 18. Esas series aparecen representadas en los gráficos 1 a $4^{35}$.

La evolución demográfica de la Extremadura moderna puede dividirse en tres grandes etapas: la primera, 1500-1574, y la última, 1652-1835, caracterizadas por la tendencia ascendente de la población, mientras que en la segunda, 1575-1651, se registró un intenso movimiento depresivo -en los gráficos se observan claramente la segunda y la tercera-. Convendría, sin embargo,

"Ello no va a ser impedimento para que intentemos pronto añadir a la muestra los registros bautismales de varias localidades pequeñas.

${ }^{34}$ De los 37 pueblos de la muestra, sólo en 20,8 de Cáceres y 12 de Badajoz, se conservan registros bautismales anteriores a 1550 . Como queríamos conocer el comportamiento de la población extremeña en el tercer cuarto del xVI, hemos manejado dos curvas para la región. Ia de 20 núcleos nos servirá exclusivamente para el análisis del referido período.

" Como en este trabajo sólo nos ocuparemos del comportamiento de la población en la larga duración, prestaremos una atención casi exclusiva a las curvas de medias móviles. No obstante, también hemos representado las series regionales y provinciales de bautizados - gráficos 1 a 4 - 


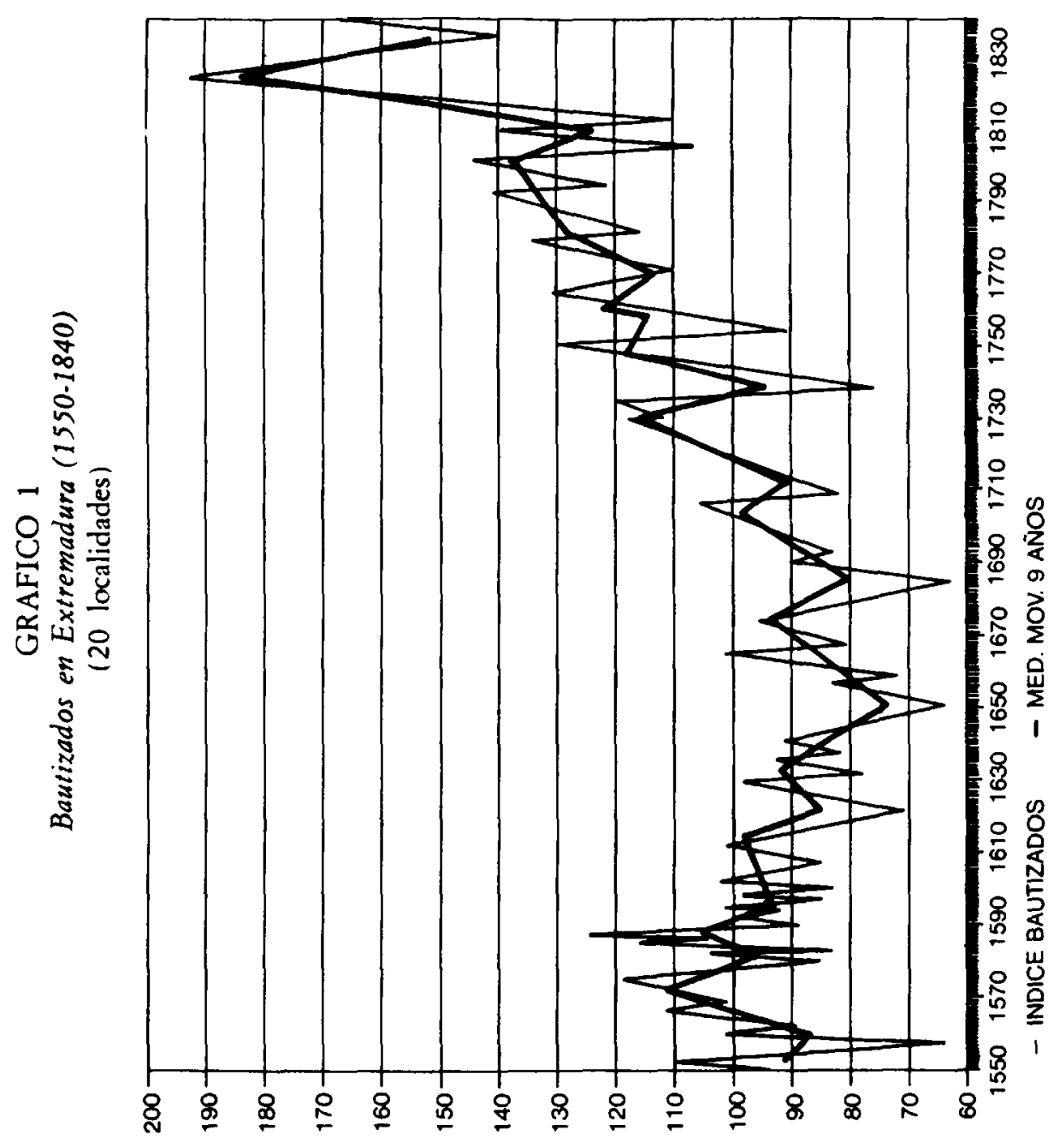




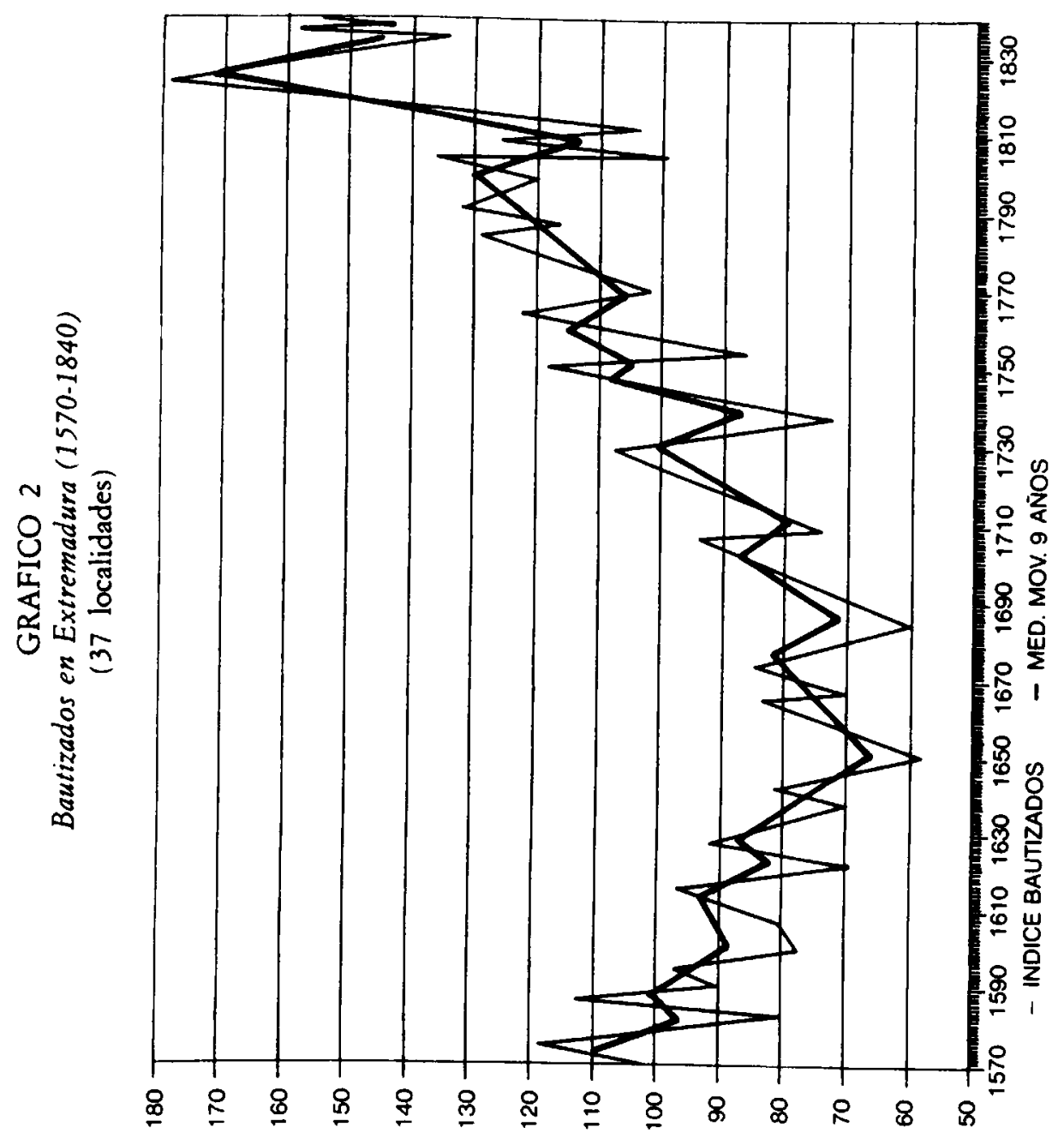


distinguir en la última dos subfases: la de recuperación, 1652-1759, hasta que se hubo recobrado el máximo de natalidad del siglo xvi, y la de auténtico auge, $1760-1835^{36}$.

Tanto las fuentes maciodemográficas ${ }^{37}$ como los registros bautismales ${ }^{38}$ apuntan a que el número de extremeños registró un incremento notable en los tres primeros cuartos del siglo xvi. Pese a ello, resulta aventurado cuantificar dicha alza, cuando la estimación se basa exclusivamente en los datos de los censos de 1528 y 1591 . En el conjunto de los 20 núcleos para los que disponemos de datos desde mediados del siglo xvi, el nivel de los bautismos se elevó un 22,89 por 100 entre 1554 y 1574 -un 11,85 por 100 en los 8 pueblos cacereños y un 25,96 por 100 en los 12 pacenses-. Aunque la representatividad de esta muestra es cuestionable ${ }^{39}$, todo parece indicar que el crecimiento demográfico prosiguió en la región a un ritmo rápido durante el tercer cuarto del siglo xvi, si bien la intensidad del movimiento expansivo era mucho mayor en Badajoz que en Cáceres ${ }^{* 0}$.

La depresión, que se había iniciado en fechas relativamente tempranas, fue de gran magnitud y duradera: entre 1570-1578 y 1647-1655 el número de bautizados en las 37 localidades se redujo un 39,22 por 100. Tan larga etapa de acusada tendencia descendente puede dividirse en siete subperíodos, cuatro contractivos (1574-1582, 1588-1601, 1614-1623 y 1631-1651) y tres de leve recuperación (1582-1588, 1601-1614 y 1623-1631). En los primeros, la caída del nivel de los bautismos siempre superó el 10 por 100, alcanzándose un descenso del 22,7 por 100 entre 1631 y 1651 . Por el contrario, en ninguno de los segundos se rebasó el 6 por 100 de crecimiento. De modo que el movimiento depresivo presenta una forma bastante parecida a una escalera de cuatro peldaños — véase el gráfico 2-, siendo el desnivel del último, 16311651 , casi el doble del de los tres primeros. Si utilizamos la división secular para descomponer en dos fases esta larga etapa de regresión demográfica,

${ }^{16}$ Como nada más alcanzarse el máximo del siglo xvi se entró en un subperiodo contractivo, la etapa de auténtico auge se inició realmente en 1770 .

${ }^{37}$ Nos referimos fundamentalmente a los censos de 1528 y 1591. Véase E. García España y A. Molinić-Bertrand (1983), pp. 369-389.

${ }^{3}$ Disponemos de los registros de varios pueblos correspondientes al segundo cuarto del siglo XVI, pero la muestra que podría formarse sería demasiado exigua para realizar una estimación del crecimiento mínimamente fundamentada. En cualquier caso, todas las series de ese intervalo, con la excepción de Guadalupe, presentan una tendencia ascendente.

39 Las curvas de 20 y 37 localidades presentan algunas diferencias. Por ejemplo, la fecha de recuperación del máximo del siglo xvi -1728 en el primer caso y 1759 en el segundo-. Por consiguiente, nuestra cautela deberá aumentar cuando extraigamos conclusiones basadas en la primera.

* Paradójicamente, la inversión de la tendencia parece producirse un par de años antes en Badajoz que en Cáceres - 1573 y 1575, respectivamente-. 


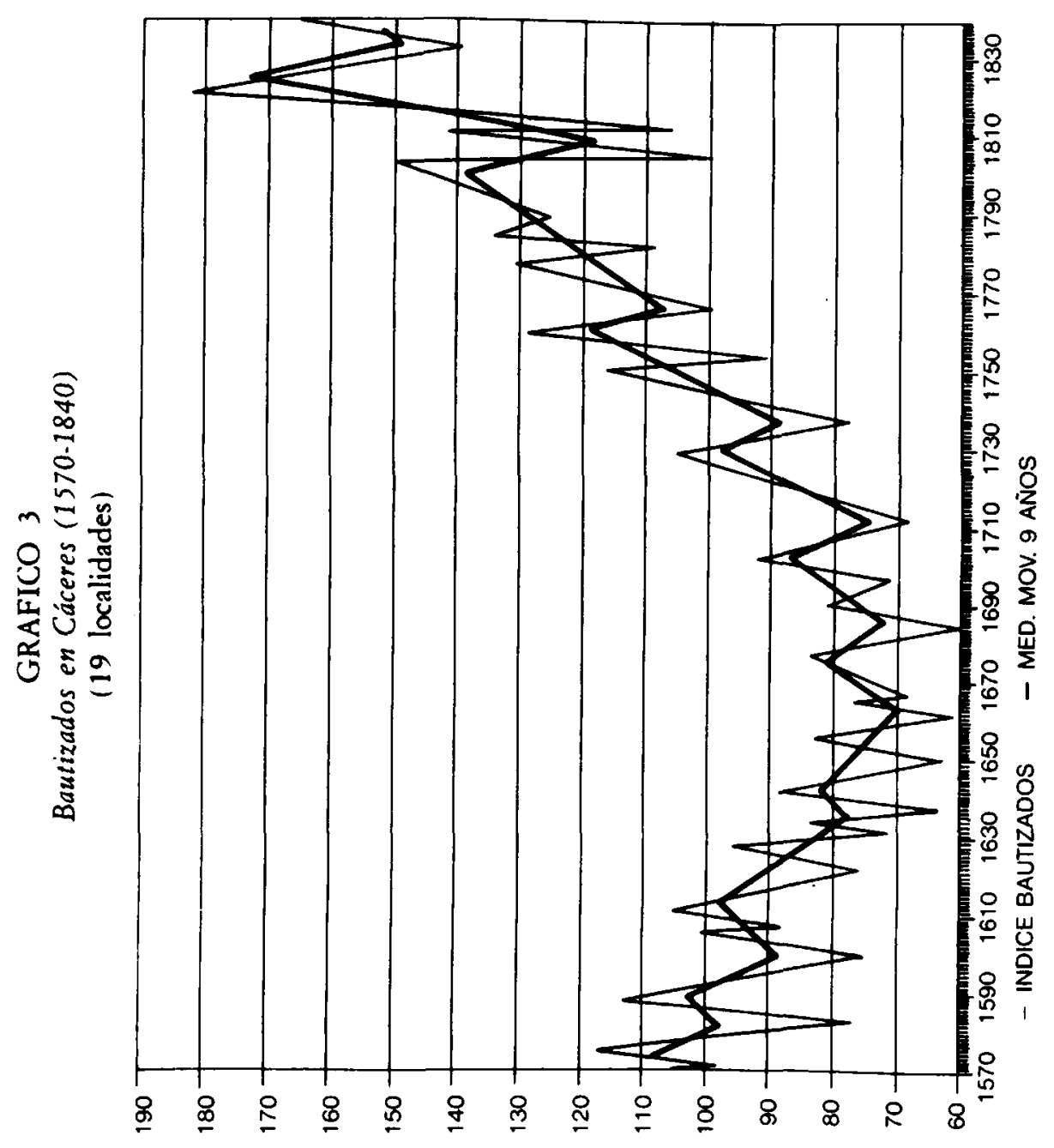




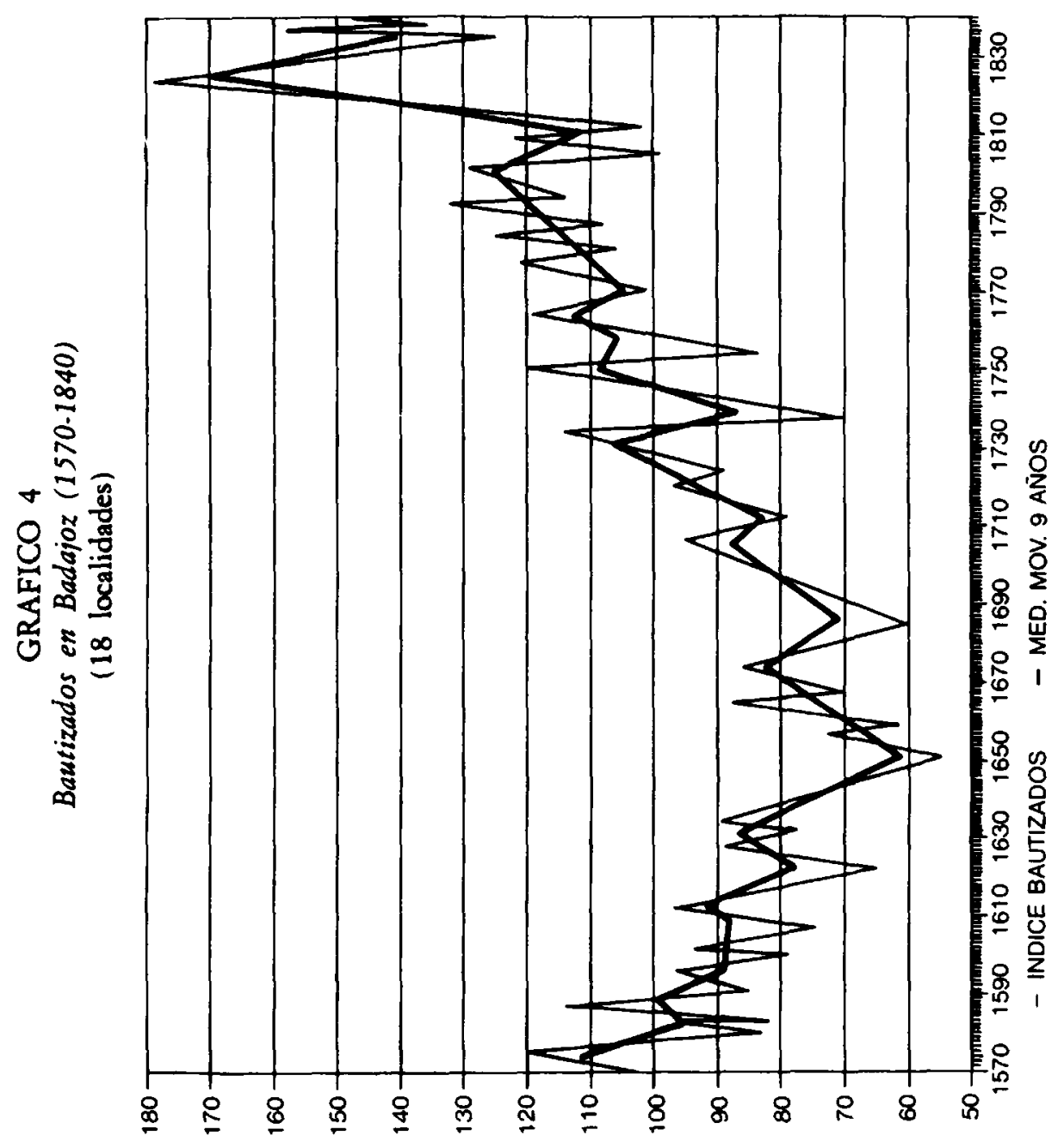


resulta que el número de bautizados descendió un 18,35 por 100 entre 1570 . 1578 y 1596-1604, y un 25,56 por 100 entre 1596-1604 y 1647-1655. Consiguientemente, la región parece haber perdido ya un número apreciable de efectivos en el último cuarto del siglo $x^{2}{ }^{41}$.

A partir de mediados del siglo xvir, la población extremeña iniciará una larguísima etapa de signo positivo, que se prolongará hasta finales del Antiguo Régimen ${ }^{42}$; ahora bien, la recuperación de los máximos de natalidad del siglo xvı tardará más de una centuria en acontecer, debido a los importantes frenos al crecimiento demográfico. En esta extensísima etapa de tendencia alcista detectamos seis subperíodos expansivos y, también, seis contractivos.

\section{CUADKO 2}

\begin{tabular}{|c|c|c|c|c|c|}
\hline \multicolumn{3}{|c|}{ FASES EXPANSIVAS } & \multicolumn{3}{|c|}{ IAASES CONTRACTIVAS } \\
\hline Periodos & Duración & $\begin{array}{c}\text { Creci } \\
\text { miento }\left(\omega_{0}\right)\end{array}$ & Periodos & Duración & $\begin{array}{c}\text { Creci } \\
\text { miento (9o) }\end{array}$ \\
\hline \multirow[t]{2}{*}{$\begin{array}{l}1652-1676 \\
1686-1703 \\
1713.1730 \\
1740.1760 \\
1771-1800 \\
1810.1825\end{array}$} & $\begin{array}{l}25 \\
18 \\
18 \\
21 \\
30 \\
16\end{array}$ & $\begin{array}{l}22,+40 \\
21,56 \\
28,12 \\
30,63 \\
22,30 \\
50,36\end{array}$ & $\begin{array}{l}1677-1685 \\
1704-1712 \\
1731-1739 \\
1761-1770 \\
1801-1809 \\
1826-1835\end{array}$ & $\begin{array}{r}9 \\
9 \\
9 \\
10 \\
9 \\
10\end{array}$ & $\begin{array}{r}11,83 \\
8,80 \\
13,92 \\
7,10 \\
12,95 \\
15,11\end{array}$ \\
\hline & 128 & & & 56 & \\
\hline
\end{tabular}

Fuentes: Elaboración propia a partir de los datos del cuadro A.2 del Apéndice estadístico.

Si nos fijamos en la fase anterior a 1760 , podremos constatar que la duración de los subperíodos de signo positivo fue netamente superior a la de los de signo opuesto. Sin embargo, el movimiento restaurador no cobró auténtico vigor hasta 1712: en esa fecha sólo se había recuperado el 30,43 por 100 de la caída que se había producido entre 1574 y 1651 . En consecuencia, la mayor parte de la restauración demográfica tendría lugar después de 1712. Ahora bien, pese a la indudable aceleración del crecimiento a raíz de la finalización del conflicto sucesorio, la profunda crisis de los treinta, provocada por la sobremortalidad de $1734-1735$ y por las pésimas cosechas de $1737-1738^{43}$,

" Es muy probable que la caida del número de habitantes fuese inferior a ese 18,35 por 100 , ya que la tasa de natalidad debió descender algo entre 1574 y 1600 .

"2 Ese movimiento ascendente se va a prolongar, en realidad, hasta los años sesenta del siglo $x x$.

^M. A. Melón (1989), pp. 69 y 82; E. Llopis (1989), pp. 269 y 275-276. 
vino a desbaratar buena parte del avance de las dos décadas precedentes. Todo ello contribuye a explicar por qué el movimiento de recuperación fue bastante más lento que el depresivo.

$\mathrm{Ni}$ las guerras ni la mortalidad catastrófica parecen ser los principales motivos de los casi dos siglos que tardó la región en recobrar el máximo de bautizados del siglo xvı. En cuanto a los conflictos bélicos, resulta significativo que la natalidad toque fondo bastante antes de concluir la guerra con Portugal y que la curva de bautizados de la zona Oeste, la más afectada por aquéllos, no presente diferencias sustanciales con respecto a las del Centro y Este de la región ". Por otro lado, un reciente trabajo de A. Rodríguez Grajera ${ }^{45}$ corrobora para la Alta Extremadura las tesis de V. Pérez Moreda: 1) la incidencia de las crisis de mortalidad en la trayectoria demográfica de la España moderna fue bastante menor de lo que ha venido suponiéndose tradicionalmente, y 2) el siglo xvir no fue una época en la que la mortalidad catastrófica alcanzara una intensidad especialmente elevada.

Sin olvidar el movimiento migratorio, del que sabemos todavía muy poco, las evidencias disponibles apuntan a que el hundimiento demográfico, primero, y la lentitud de la recuperación, más tarde, se debieron fundamentalmente al comportamiento de la fecundidad. El descenso de la tasa de natalidad y su mantenimiento en niveles relativamente bajos durante un largo período de tiempo, hubo de obedecer, ante todo, a los graves problemas económicos que padecieron gran parte de los extremeños en las décadas finales del siglo xvi $y$ en el xvir. En este sentido, las cabañas trashumantes no pudieron ser la causa básica de esas tremendas dificultades: el número de cabezas mesteñas se mantuvo en niveles bastante reducidos entre 1570 y $1720^{40}$; será a partir de 1750 cuando la expansión de la ganadería trashumante tenga un papel protagonista en la crisis de crecimiento de la economía extremeña ${ }^{47}$. Por ello, la fragilidad de las explotaciones campesinas de la región, al menos durante el siglo xvil, debemos buscarla, entre otros factores, en la presión fiscal y, sobre todo, en las posibilidades y condiciones de acceso de aquéllas a labrantíos y pastizales.

El balance demográfico del siglo xvin fue bastante más favorable para la región, pero conviene no olvidar que el máximo de bautizados del siglo xvI

“ No obstante, el descalabro de los años treinta y cuarenta fue de mayor entidad en el Oeste que en el Centro y Este. Además, cuando se observa la curva de los núcleos cacereños, sí sc detecta un comportamiento claramente diferencial de los de la zona Oeste: depresión más larga c intensa y recuperación mucho más lenta.

* A. Rodriguez Grajera (1989), p. 15.

to J. P. Le Flem (1972), pp. 68-69. El movimiento depresivo de las exportaciones de lana tocará fondo después de 1650 . Véase L. M. Bilbao (1983), p. 227.

"E. Llopis (1989), pp. 277-279; M. A. Melón (1989), pp. 109.111 y 209-212. 
no se recobraría hasta finales de los cincuenta. Además, el nivel de la natalidad volvió pronto a situarse por debajo de dicho máximo en el transcurso de la crisis de los sesenta, pese a que ésta no revistió la intensidad de la de

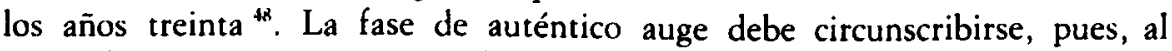
intervalo 1770-1835. Este se abriría con un largo subperiodo de tendencia suavemente ascendente del número de bautizados: el escaso dinamismo agrícola estaba haciendo muy difícil el mantenimiento del alza de la población, si bien el movimiento expansivo prosiguió hasta finales de siglo. El Real Decreto de 28 de abril de 1793, que declaró las dehesas extremeñas de pasto y labor, constituyó un alivio para la agricultura de la región, en la medida en que facilitó un incremento del área cultivada mediante la aplicación del mismo o, más frecuentemente, a través de las ocupaciones y roturas de fincas llevadas a cabo por amplios colectivos de campesinos, a veces bien organizados, en un número considerable de pueblos ${ }^{49}$.

Las desastrosas cosechas de 1803-1805, las crisis de mortalidad y la Guerra de la Independencia provocaron la paralización del crecimiento de la natalidad. Este subperíodo contractivo duró casi una década y alcanzó una intensidad sólo algo inferior a la de los años treinta del Setecientos.

Extremadura registraría una auténtica explosión demográfica nada más concluir el conflicto bélico con los franceses: en 1825 el nivel medio de los bautismos era un 50,36 por 100 superior al de 1809 y un 30,87 por 100 mayor que el de 1800 -este último, máximo del subperíodo expansivo anterior-. Es casi seguro que la tasa de natalidad se incrementara de manera sensible durante esos años de euforia demográfica, lo que implicaría que el alza de la población fuera de menor entidad que la del número de bautizados. En cualquier caso, resulta muy probable que la región elevara sus efectivos humanos por encima del 25 por 100 en menos de dos décadas. Tal explosión demográfica parece venir facilitada por la fiebre roturadora acaecida al hilo del hundimiento del Antiguo Régimen y de las explotaciones trashumantes ${ }^{\mathbf{5}}$. En Extremadura, consiguientemente, la caída del viejo sistema entrañó cambios sustanciales en la distribución y formas de aprovechamiento de los recursos agrarios y, por ende, propició alteraciones importantes en los comportamientos vitales de los habitantes de la región.

La contracción del número de bautizados en los últimos años del Antiguo Régimen parece tener relación con los excesos que habían tenido lugar en el período anterior de euforia, con las menores posibilidades roturadoras, con la

4 E. Llopis (1989), pp. 269.270 y 276.

4 J. García Pérez y F. Sánchez Marroyo (1984), pp. 215-229; M. Rodriguez Cancho (1985), pp. 186-190; M. A. Melón (1988), pp. 171-181.

s E. Llopis (1982), pp. 70-76; E. Llopis (1985), pp. 140-141. 
desvalorización de los granos ${ }^{51}$ y con la crisis epidémica de $1834^{52}$. Es muy probable, pues, que la tasa de natalidad registrara un ajuste a la baja durante los años treinta del siglo xix. De ahí que la caída relativamente importante del número de bautizados sólo debió comportar un estancamiento, o un pequeno descenso, de los efectivos humanos de la región.

En suma, el desmoronamiento del Antiguo Régimen marcó una importante fractura en la economía y en la demografía extremeñas: a taíz de la Guerra de la Independencia, la tasa de natalidad se elevó de manera aprecia-

\section{CUADRO 3}

Medias decenales de bautismos expresadas en números indice (Base: media de $1590-1599=100$ )

\begin{tabular}{|c|c|c|c|c|c|}
\hline Decenios & $A$ & B & $C$ & $D$ & $E$ \\
\hline $1570-1579 \ldots \ldots$ & - & - & - & 118,14 & - \\
\hline $1580-1589 \ldots \ldots$ & 96,28 & - & 103,05 & 107,31 & 116.51 \\
\hline $1590-1599 \ldots \ldots$ & 100,00 & 100,00 & 100,00 & 100,00 & 100,00 \\
\hline $1600-1609 \ldots \ldots$ & 98,35 & 101,21 & 92,03 & 97,30 & 93,96 \\
\hline $1610-1619 \ldots \ldots$ & 93,68 & 91,18 & 99,34 & 101,00 & 91,77 \\
\hline $1620-1629 \ldots \ldots$ & 93,93 & 82,91 & 98,99 & 90,60 & 98,41 \\
\hline $1630-1639 \ldots \ldots$ & 87,46 & 65,65 & 90,44 & 89,44 & 98,96 \\
\hline $1640-1649$ & 77,53 & 76,21 & 103,35 & 82,55 & 97,87 \\
\hline $1650-1659$ & 87,28 & 69,65 & 96,17 & 73,76 & 107,63 \\
\hline $1660-1669 \ldots \ldots$ & 88,76 & 77,20 & 84,64 & 80,27 & 106,86 \\
\hline $1670-1679 \ldots \ldots$ & 88,64 & 99,62 & 80,29 & 87,94 & 108,86 \\
\hline $1680-1689 \ldots \ldots$ & 87,68 & 84,82 & 75,81 & 79,47 & 100,72 \\
\hline $1690-1699 \ldots \ldots$ & 92,73 & 90,67 & 80,33 & 85,61 & 107,61 \\
\hline $1700-1709 \ldots \ldots$ & 86,60 & 96,08 & 84,49 & 92,82 & 118,10 \\
\hline $1710-1719 \ldots \ldots$ & 90,29 & 91,18 & 86,92 & 90,89 & 119,03 \\
\hline $1720-1729 \ldots \ldots$ & 100,73 & 107,43 & 99,77 & 104,81 & 133,70 \\
\hline $1730-1739 \ldots \ldots$ & 91,17 & 102,76 & 97,99 & 101,10 & 134,53 \\
\hline $1740-1749 \ldots \ldots$ & 91,12 & 103,38 & 119.33 & 108,86 & 143,29 \\
\hline $1750-1759 \ldots \ldots$ & 99,36 & 110,33 & 125,72 & 118,91 & 157,38 \\
\hline $1760-1769 \ldots \ldots$ & 104,86 & - 114,96 & 130,87 & 119,57 & 167,39 \\
\hline $1770-1779 \ldots \ldots$ & 110,20 & 117,83 & 126,41 & 124,43 & 170,18 \\
\hline $1780-1789 \ldots \ldots$ & 112.11 & 126,29 & 136,30 & 129,60 & 170,90 \\
\hline
\end{tabular}

A: 28 localidades de Castilla la Nueva.

B: 15 localidades de Castilla la Vieja.

C: 10 localidades de León.

D: 37 localidades de Extremadura.

E: 13 localidades de Andalucía.

Fuentes: Para Extremadura, las del cuadro A.2 del Apéndice e tadístico y para el resto de regiones J. Nadal (1988), pp. 47.52.

"1 Algunas de las dehesas que habian sido roturadas tuvieron que ser dedicadas de nuevo a puro pasto a finales de los veinte debido a la intensa caida del precio de los cereales. E. Llopis (1985), p. 141.

s2 V. Pérez Moreda (1980), pp. 396-397. 
ble al beneficiarse las familias de la región de mayores posibilidades de acceso a los recursos agrarios y de una demanda de trabajo en alza, propiciada por el aumento de la superficie cultivada; todo ello, junto a la mitigación de las crisis de mortalidad, permitió alcanzar el crecimiento de población más rápido, con gran diferencia, de todo el período objeto de análisis de este trabajo ${ }^{53}$.

\section{CUADRO 4} Cronologia de máximos y minimos decenales y crecimientos y descensos
del número de bautizados

\begin{tabular}{|c|c|c|c|c|}
\hline Región & $A$ & $B$ & $C$ & $D$ \\
\hline 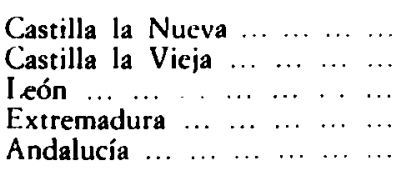 & $\begin{array}{l}1590-1599 \\
1600-1609 \\
1580-1589 \\
1570-1579 \\
1580-1589\end{array}$ & $\begin{array}{l}1640-1649 \\
1630-1639 \\
1680-1689 \\
1650 \cdot 1659 \\
1610 \cdot 1619\end{array}$ & $\begin{array}{l}22,47 \\
35,13 \\
29,83 \\
37,50 \\
21,23\end{array}$ & $\begin{array}{r}12,11 \\
24,78 \\
26,14 \\
9,70 \\
46,68\end{array}$ \\
\hline
\end{tabular}
A: Máximo de finales del xvi-comienzos del xvil.
B: Mínimo del siglo xvis.
C: Descenso entre A y $B$ (en porcentajes).
D: Decrecimiento entre $\mathrm{A}: \mathrm{y}$ el máximo decenal del siglo xvir (en porcentajes).

FueNTES: Las del cuadro anterior.

Utilizando los datos aportados por $\mathrm{J} \mathrm{Nadal}^{54}$ y los nuestros hemos elaborado los cuadros 3 y 4 , con el propósito de comparar la curva de bautizados de Extremadura con las de otras regiones de la Corona de Castilla ${ }^{55}$. En espera de nuevos estudios regionales sustentados en muestras más amplias y representativas ${ }^{56}$, las cifras de dichos cuadros nos sugieren las siguientes conclusiones:

"Debido a la escasísima densidad demográfica de Extremadura a comienzos de los tiempos modernos - véase E. Cabrera y G. Lora (1984), pp. 63-75-, resulta altamente probable que la población regional creciese también a una elevada tasa durante la primera mitad del siglo xvi.

st J. Nadal (1988), pp. 47.52.

s Los resultados de las comparaciones tienen necesariamente un carácter muy provisional. Por un lado, la dimensión temporal de las series de las dos Castillas, León y Andalucía no permite saber con certeza el momento en que el crecimiento del Quinientos tocó techo; por otro, las muestras de localidades de las series de Nadal, como él mismo comenta, no son suficientemente amplias ni completas.

S. Sería conveniente que esas investigaciones cubrieran, cuando menos, el período 1550 1840. De ese modo se podría obtener una visión bastante completa sobre la evolución demográfica durante el Antiguo Régimen. 
1. El crecimiento de la población del Quinientos parece tocar techo antes en Extremadura, León y Andalucía que en las dos Castillas ${ }^{57}$.

2. $\quad$ La depresión demográfica del siglo xviI alcanzó las máximas proporciones en Extremadura y Castilla la Vieja y las mínimas en Andalucía y Castilla la Nueva ${ }^{58}$, ocupando León una posición intermedia. La caída del número decenal de bautismos osciló entre el 21,23 por 100 de Andalucía y el 37,56 por 100 de Extremadura.

3. ${ }^{\mathrm{L}}$ La duración del movimiento contractivo registró los máximos en Extremadura y León y los mínimos en Castilla la Vieja y Andalucía.

4. ${ }^{\mathrm{a}}$ La recuperación del máximo decenal de finales del siglo xvi o de comienzos del xviı se produjo en 1700-1709 en Andalucía, en 1720-1729 en las dos Castillas, en 1740-1749 en León y en 1750-1759 en Extremadura. En general, el movimiento restaurador fue lento en todas las regiones; a este fenómeno debe otorgársele tanta o más importancia que a la entidad del movimiento depresivo.

5. El balance demográfico de los siglos xviI y xviII fue mucho más favorable para Andalucía que para Castilla la Nueva y Extremadura.

En síntesis, aun cuando en ninguna de las regiones contempladas el comportamiento de la población puede ser calificado de brillante, prácticamente todas las comparaciones resultan desfavorables para Extremadura.

\section{Los comportamientos diferenciales de la natalidad}

Hemos efectuado diversas desagregaciones de la serie regional de bautizados en 37 localidades con el propósito de detectar posibles comportamientos diferenciales de la natalidad que tuvieran su origen en la jurisdicción, topografía, grado de proximidad a la frontera o tamaño de los pueblos - véase cuadro A.1 del Apéndice estadístico-. Debemos reconocer que el sesgo de la muestra en favor de Badajoz suele provocar que las distintas series regionales desagregadas vengan más marcadas por la trayectoria general de los núcleos pacenses que por la de los cacereños. De ahí que hagamos alusión a las diferencias provinciales cuando éstas sean notorias ${ }^{59}$.

"Castilla la Vieja of rece contrastes dignos de mención: el máximo se alcanzó antes de 1570 en la provincia de Segovia, mientras que ello ocurrió después de 1605 en Tierra de Campos. Véanse A. García Sanz (1978), pp. 54-55, y B. Yun (1985), p. 29.

s La no inclusión de ninguna localidad de Ciudad Real probablemente introduzca un sesgo en la serie de Castilla la Nueva. En La Mancha, el movimiento depresivo de los bautismos parece ser de superior magnitud que el del resto de Castilla la Nueva. Véase J. López-Salazar (1986), pp. 57-78.

s9 En el desarrollo del trabajo hemos manejado las series provinciales desagregadas -jurisdicción, topografía, zona y tamaño-. Sin embargo, no vamos a realizar un estudio 


\section{CUADRO 5}

Cronología de máximos, minimos y de recuperación de aquéllos, crecimientos y descensos del nivel de bautizados

\begin{tabular}{|c|c|c|c|c|c|}
\hline Series & $A$ & $B$ & $C$ & $D$ & $E$ \\
\hline 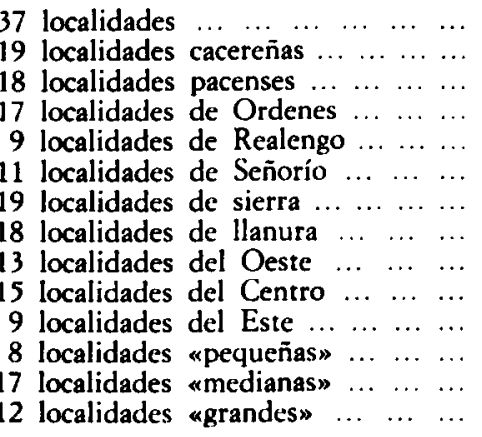 & $\begin{array}{l}1574 \\
1574 \\
1574 \\
1574 \\
1574 \\
1588 \\
1574 \\
1574 \\
1575 \\
1574 \\
1574 \\
1574 \\
1574 \\
1574\end{array}$ & $\begin{array}{l}1651 \\
1663 \\
1651 \\
1651 \\
1661 \\
1651 \\
1649 \\
1655 \\
1651 \\
1688 \\
1650 \\
1654 \\
1663 \\
1651\end{array}$ & $\begin{array}{l}1759 \\
1748 \\
1760 \\
1760 \\
1778 \\
1702 \\
1759 \\
1749 \\
1775 \\
1748 \\
1749 \\
1817 \\
1747 \\
1759\end{array}$ & $\begin{array}{l}39,22 \\
34,81 \\
44,24 \\
42,16 \\
48,37 \\
27,35 \\
42,04 \\
37,45 \\
42,18 \\
39,93 \\
35,67 \\
50,34 \\
36,73 \\
40,09\end{array}$ & $\begin{array}{l}55,75 \\
59,81 \\
52,95 \\
54,99 \\
54,17 \\
58,52 \\
46,52 \\
68,13 \\
37,04 \\
72,24 \\
68,50 \\
22,18 \\
68,40 \\
54,15\end{array}$ \\
\hline
\end{tabular}

A: Fecha del máximo del siglo xvi.

B: Fecha del mínino del siglo xvir.

C: Fecha de recuperación del máximo del siglo xvi.

D: Descenso entre el máximo de A y el mínimo de B (en porcentajes).

E: Crecimiento entre el máximo de $\mathrm{A}$ y el máximo absoluto (en porcentajes).

Fuentes: Las del cuadro $A .2$ del Apéndice estadístico.

En el cuadro 5 presentamos algunos de los rasgos más significativos de las líneas evolutivas de las diversas series manejadas. Por su parte, en los gráficos 5 a 8 aparecen representadas las curvas regionales de bautismos desagregadas de acuerdo con los cuatro criterios empleados: jurisdicción, topografía, longitud geográfica y tamaño de los núcleos.

Analizando la desagregación por jurisdicciones podremos observar que el balance de todo el período fuy muy similar en las tres series -véase el gráfico 5-: entre 1574 y 1835 el nivel medio de los bautismos creció un 35,41 por 100 en las localidades de realengo, un 31,16 por 100 en las de órdenes y un 35,52 por 100 en las de señorío. Sin embargo, el perfil de las tres curvas presenta importantes contrastes. Hasta 1700 , el mejor comporta-

singularizado de las mismas: en primer lugar, porque nuestro propósito fundamental estriba en determinar las pautas regionales; en segundo lugar, porque los problemas de representatividad de la muestra se multiplican cuando ésta se emplea para el examen individualizado de diversas porciones del conjunto regional. 


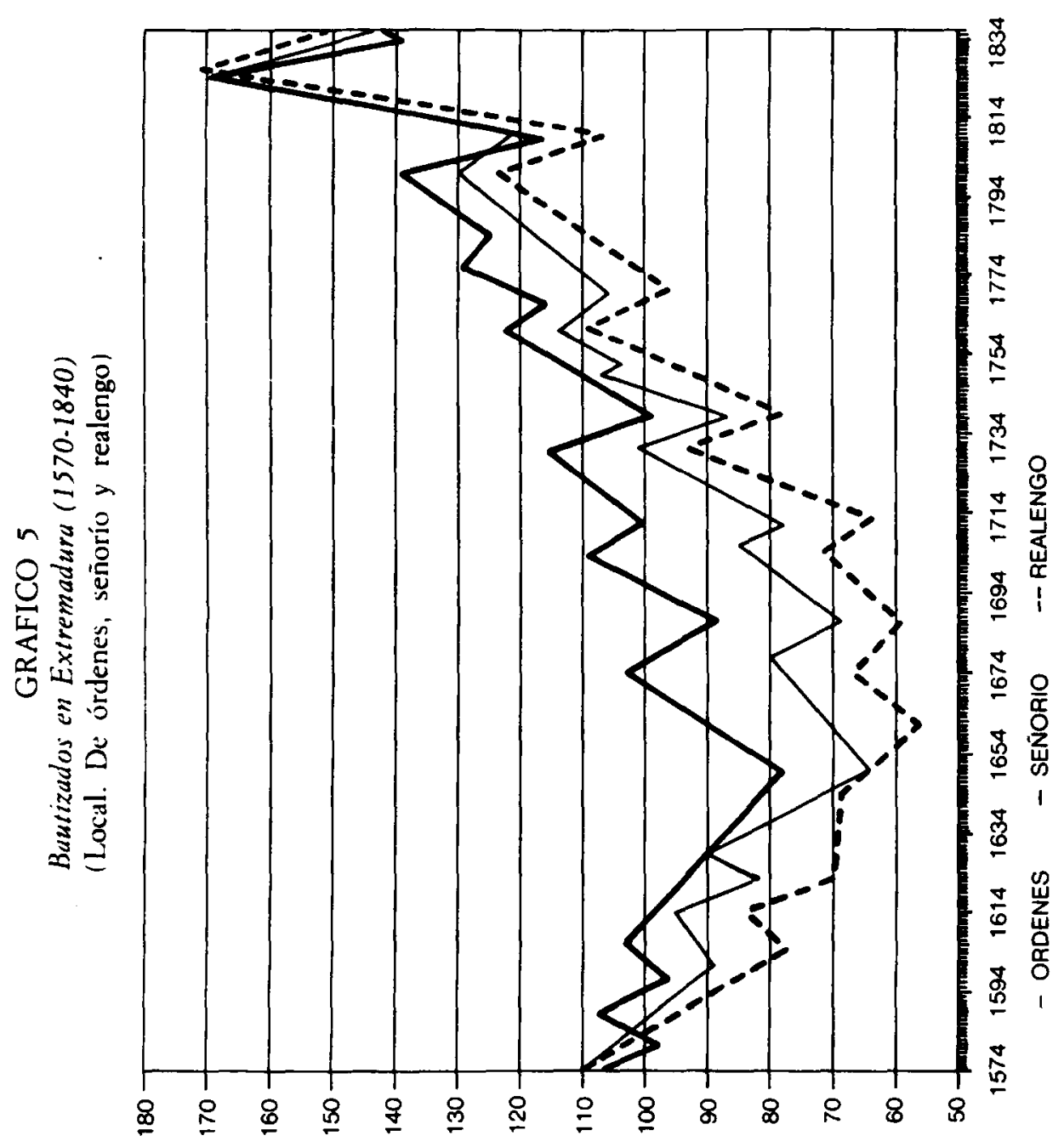

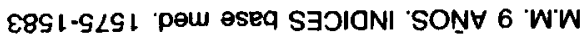


miento demográfico correspondió a los núcleos de señorío. En ellos la tendencia alcista de la población del Quinientos se prolongó hasta finales de los ochenta, y el movimiento depresivo fue de bastante menor magnitud que el registrado por las localidades realengas o de órdenes. Por el contrario, la expansión demográfica del siglo xviII y del primer tercio del xix alcanzó menor entidad en los territorios de señorío que en los de órdenes y realengo ${ }^{60}$.

La trayectoria de la etapa depresiva también presenta perfiles singulares. En los pueblos de realengo el movimiento contractivo fue muy intenso en el último cuarto del siglo xvi: más del 58 por 100 del descenso en el nivel de los bautizados se concentró entre 1574 y 1601 . En las localidades de órdenes la depresión fue suave hasta 1632 y muy intensa en las dos décadas siguientes.

Las curvas de natalidad de los núcleos de sierra y de llanura presentan bastantes más semejanzas que diferencias, hasta el punto de que ambas, prácticamente, se superponen entre 1655 y 1760 . No obstante, en la etapa depresiva y en la de auge encontramos algunos contrastes; por un lado, la primera revistió mayor magnitud en las localidades de sierra que en las de llano (véase gráfico 6), afirmación que no se puede hacer extensiva a los núcleos cacereños; por otro, la segunda alcanzó más brillantez en éstas que en aquéllas. Es lógico, pues, que el balance demográfico de todo el período resultase más favorable para los núcleos de llanura que para los de sierra: entre 1574 y 1835 el nivel de los bautismos creció un 42,33 por 100 en los primeros $y$ un 24,66 por 100 en los segundos.

La curva de bautismos de los núcleos más próximos a la frontera con Portugal presenta marcadas diferencias con respecto a las de los núcleos del centro y de la parte oriental de Extremadura. Sin embargo, el periodo de signo más negativo, en términos relativos, para la zona occidental fue la segunda mitad del siglo xviII, época en la que el territorio regional no se vio envuelto en ningún conflicto bélico ${ }^{61}$. Entre 1747 y 1800 los bautismos crecieron a una tasa del 0,25 por 100 en el Oeste, del 0,47 por 100 en el Centro y del 0,49 por 100 en el Este ${ }^{62}$. Por tanto, no parece que las guerras

En Cáceres, las curvas de realengo y órdenes presentan grandes similitudes hasta 1714. A partir de dicha fecha la expansión será mucho más rápida en el territorio de jurisdicción realenga. En Badajoz, por el contrario, la mayor tasa de crecimiento se alcanzó en los núcleos de órdenes.

- Las zonas fronterizas fueron las más castigadas por los conflictos bélicos. Véanse A. Rodríguez Sánchez (1979), pp. 605-625, y F. Zarandieta (1983), pp. 121-122. Si la guerra hubiese sido un factor decisivo en el comportamiento demográfico a largo plazo, $\mathrm{cl}$ periodo más negativo en términos relativos hubiera sido la segunda mitad del siglo xvir y las primeras décadas del xviII.

*2 En la zona Oeste de la región los mesteños aprovechaban grandes extensiones de pastizales, pero la explicación de ese comportamiento demográfico diferencial no debió radicar sólo en la amplia presencia de los rebaños trashumantes en los territorios cercanos a la frontera. Véase M. A. Melón (1989), pp. 192-196. 


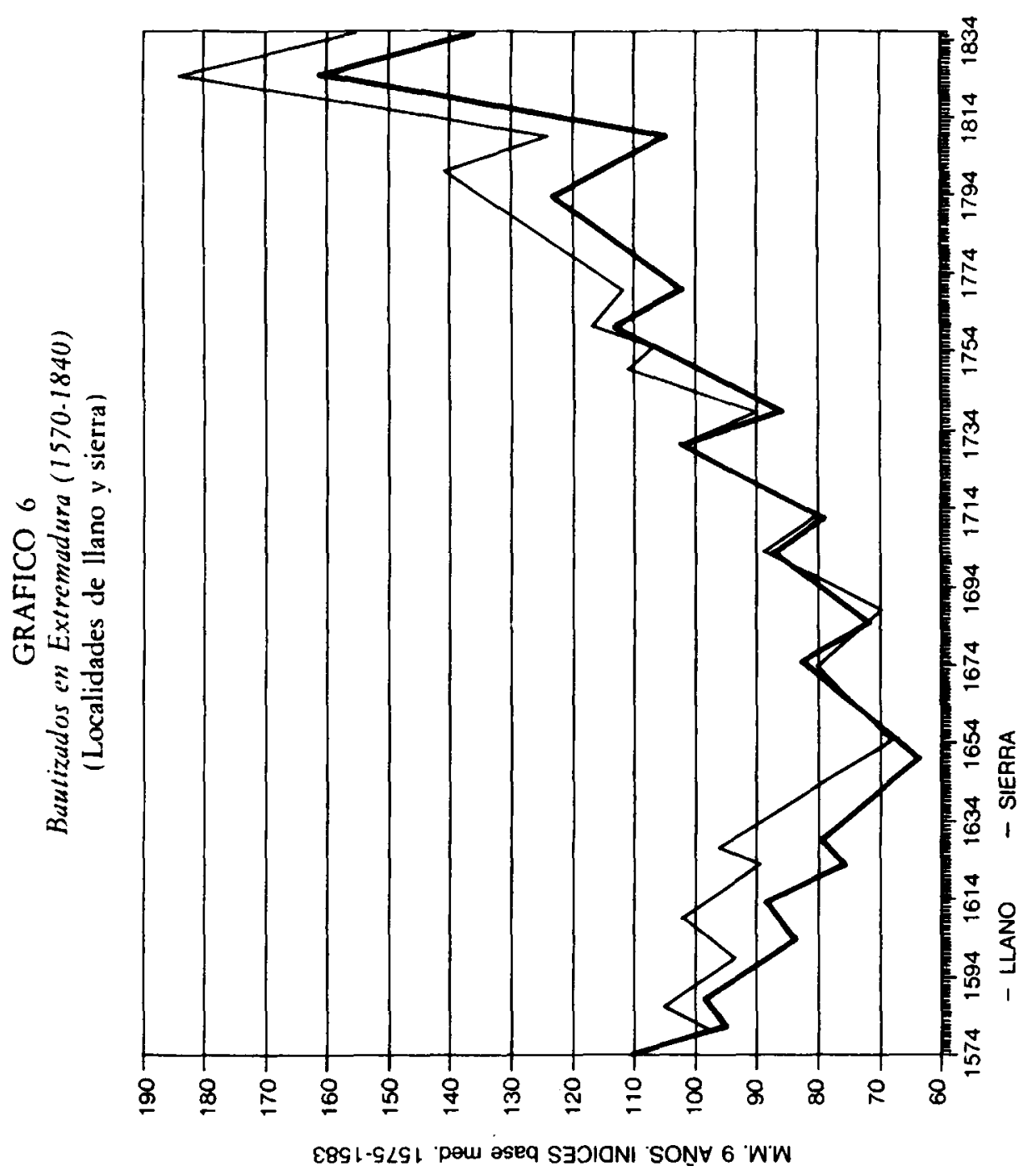




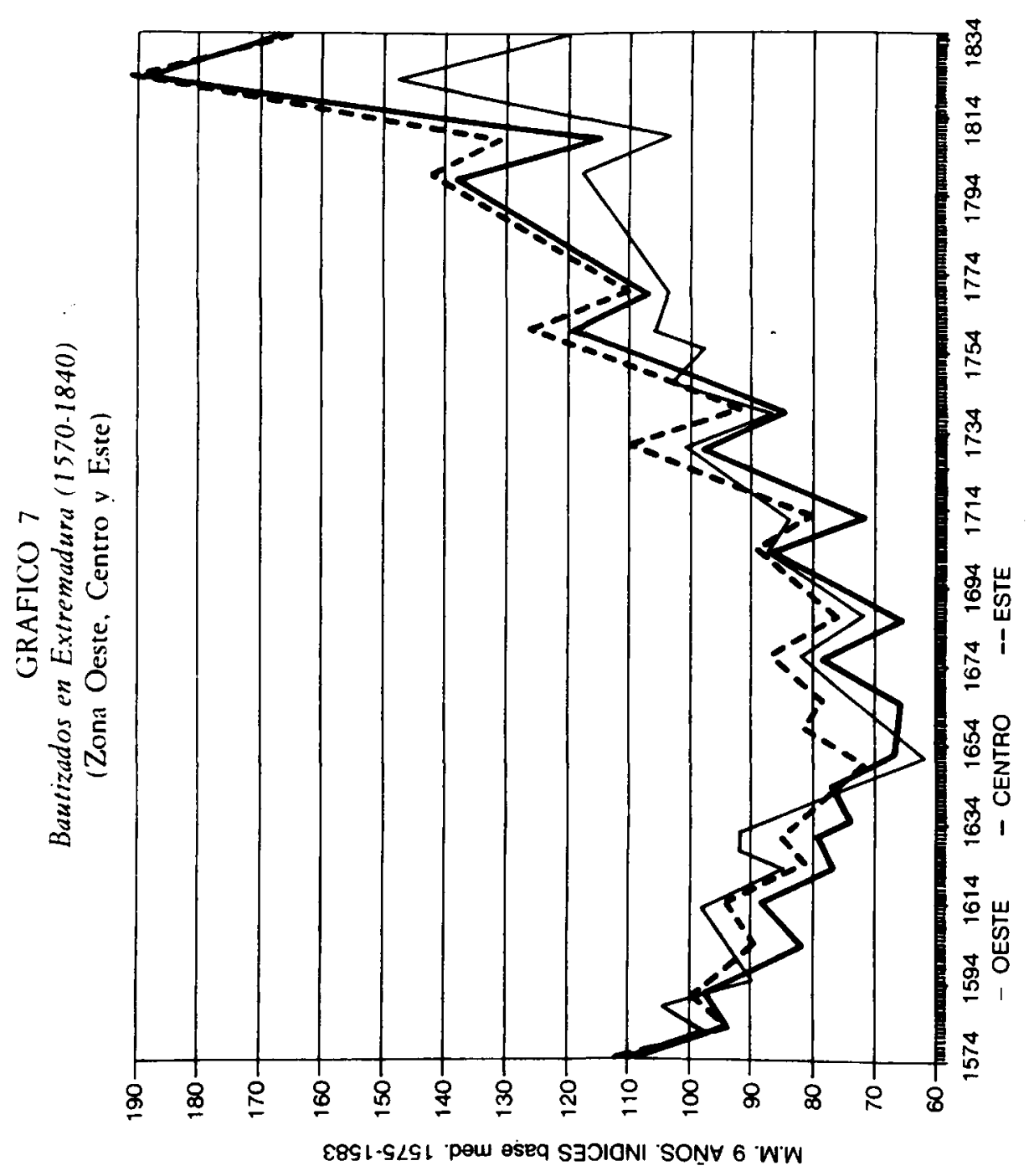


hayan constituido el factor clave de la diferente evolución demográfica a largo plazo en las distintas zonas extremeñas.

El movimiento depresivo alcanzó mayor magnitud en el Oeste -aun cuando la natalidad en esta zona se comportó de manera menos negativa que la de las otras dos hasta mediados de los años treinta- y menor en el Este. pero fue en el Centro donde aquél registraría la máxima duración ${ }^{63}$-véase el gráfico 7- El hundimiento demográfico se concentró más en el tiempo en el Oeste que en el Centro y Este; en los núcleos cercanos a la frontera. el 65,30 por 100 de la caida de los bautismos se produjo entre 1632 y 1651 . Antes de que concluyera la guerra con Portugal tuvo lugar una vigorosa recuperación en las localidades pacences de la zona (Jeste, aunque en las cacereñas la recuperación sería más tardía y nada vigorosa. Se confirman, una vez más, las distintas secuelas demográficas de los conflictos bélicos en la época moderna en el corto y en el largo plazo: considerables en el primer caso y menos relevantes, casi siempre, en el segundo.

Es difícil aventurar si el tamaño de los núcleos fue un factor relevante en su evolución demográfica durante la época moderna. Por un lado, las curvas de bautismos de las localidades medianas y grandes son muy parecidas, si bien la explosión de la natalidad, después de 1814 , fue más intensa en aquéllas que en éstas -véase el gráfico $8^{\mathrm{N}}$ - ; por otro, es cierto que la trayectoria demográfica de signo más negativo fue protagonizada por los pueblos pequeños, pero la muestra, en este caso, es excesivamente exigua y, además, el comportamiento de los núcleos cacereños difiere de modo apreciable del de los pacenses "45. Por esta razón no disponemos todavía de suficientes evidencias para afirmar que la dimensión de los pueblos constituyera un factor determinante de las diferencias observadas en el comportamiento demográfico de los núcleos de la región.

En cualquier caso, los factores de alcance general parecen ejercer un im. pacto mucho mayor sobre la natalidad que aquellos otros que afectaban de manera desigual a los distintos pueblos de acuerdo con su jurisdicción, topografía, proximidad a la frontera y tamaño. En este sentido resulta revelador

a3 La crisis de los ochenta del XVII sería especialmente intensa en el centro de la región; de ahí que en esta zona el movimiento depresivo tocara fondo en dicha década.

"Aqui las similitudes de las curvas regionales tampoco se reproducen cuando se desciende a escala provincial: en Cáceres se comportaron mejor los núcleos medianos, mientras que en Badajoz sucedió lo contrario, salvo entre 1814 y 1835 , período en el que el tirón de la natalidad sería aún más intenso en aquéllos que en los grandes.

"En Cáceres, el balance más favorable de todo el período correspondió a los núcleos pequeños, en tanto que en Badajoz fueron éstos, con gran diferencia, los que tuvieron el peor comportamiento. Por tanto, hasta no ampliar la muestra de localidades pequeñas no podemos realizar comparaciones suficientemente fundamentadas entre su trayectoria demográfica y la del resto de núcleos. 


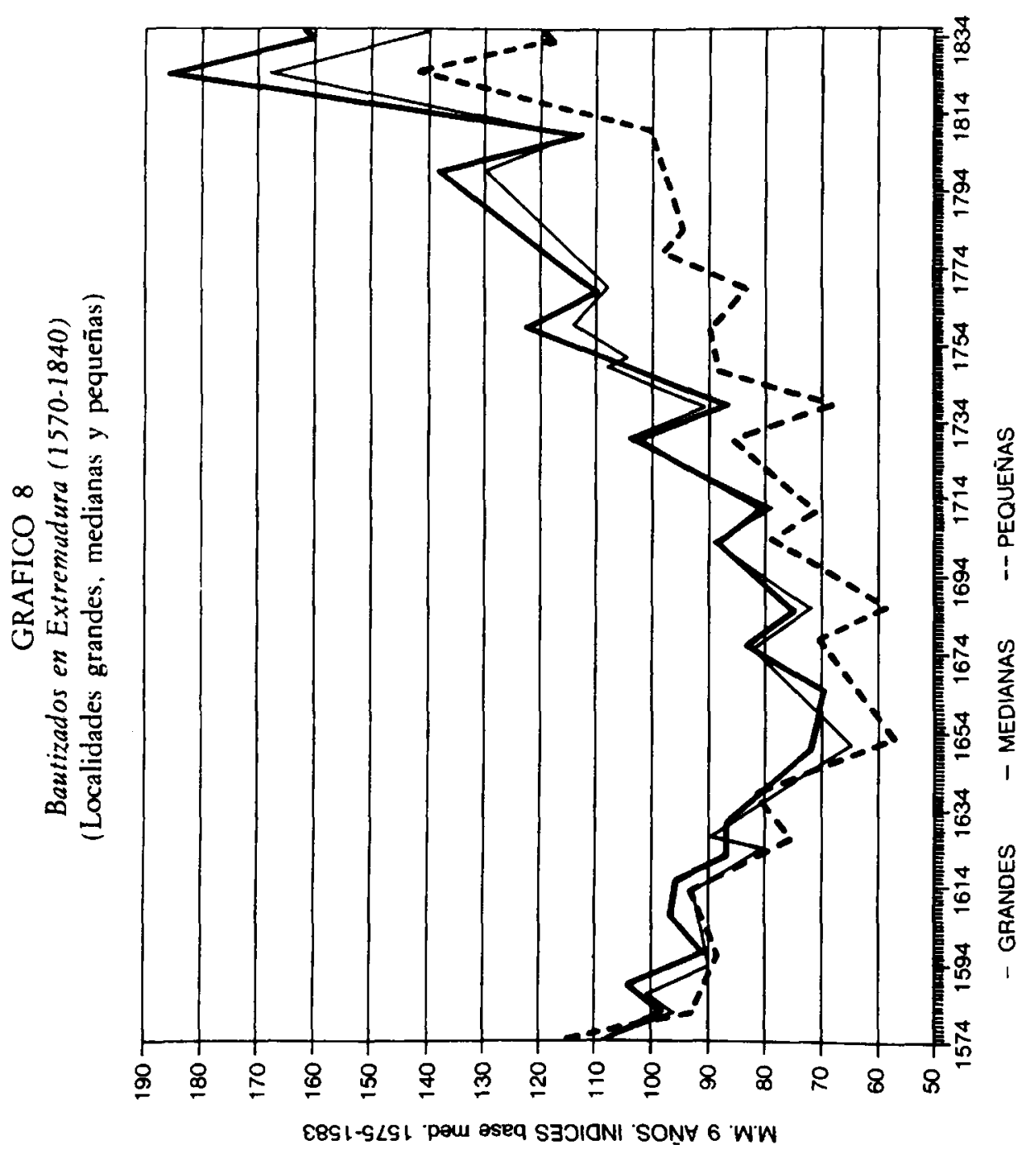


que las semejanzas de las curvas sean bastante más importantes que sus diferencias.

IV. Una estimación de los movimientos del número de babitantes en la Extremadura moderna

Nuestro objetivo último no era el conocimiento de las vicisitudes de la natalidad, sino aproximarnos a la trayectoria de la población extremeña du. rante el Antiguo Régimen. Por ello, vamos a realizar una estimación de las variaciones del número de habitantes de la región entre 1574, 1651, 1700, 1750 y $1800^{\circ 6}$.

El principal soporte de la estimación estará integrado, lógicamente, por las series de natalidad. A fin de paliar uno de los sesgos que presentaba la muestra hemos procedido a calcular los incrementos o descensos del nivel de bautizados en cada una de las provincias. Para obtener esas cifras se ha recurrido a un índice que pondera el diferente peso relativo de las localidades grandes, medianas y pequeñas en cada una de las provincias de acuerdo con los datos del Vecindario de 1591 o del Censo de 1787. Una vez estimados los incrementos o descensos del nivel de bautizados en Cáceres y Badajoz, hemos calculado los datos regionales mediante un nuevo índice ponderado ${ }^{67}$. El último paso ha consistido en suponer una tasa de natalidad para cada una de las fechas elegidas $y$, a renglón seguido, corregir los números índice de bautismos de acuerdo con las variaciones atribuidas a aquélla ${ }^{68}$.

* Hemos renunciado a estimar el crecimiento de la población en el primer tercio del siglo xix debido a que la tasa de natalidad parece registrat grandes oscilaciones en dicho período: brusco movimiento alcista en los años que siguieron a la guerra y descenso, no menos violento, en los años treinta. De no haberse producido este último, habría que admitir una caida pronunciada de la población en el conjunto de Extremadura entre 1825 y 1835 , fenómeno que, como resulta obvio, no tuvo lugar.

-2 De acuerdo con los datos del Vecindario de 1591, Cáceres y Badajoz concentraban cl 50,47 y el $+9,52$ por 100 de la población extremeña, respectivamente -suponiendo un mismo coeficiente habitantes/vecino para ambos territorios-. En 1787, según el Censo de Floridablanca, la primera albergaba el 46,29 por 100 y la segunda el 53,70 . Utilizando las cifras provinciales de 1591 y 1787 y las estimaciones sobre los aumentos o descensos de la población en Cáceres y Badajoz, hemos calculado el peso demográfico de cada una de éstas en $1574,1651,1700,1750$ y 1800.

* Hemos supuesto las siguientes tasas de natalidad: 40 por 1.000 para 1574, 37 por 1.000 para 1651 , 39 por 1.000 para 1700 y 41 por 1.000 para 1750 y 1800 . M. A. Melón ha calculado para 10 localidades cacereñas una tasa media de natalidad del 41,16 por 1.000 hacia 1752 y del 42,08 por 1.000 hacia 1790 . Véase M. A. Melón (1989), p. 50. Por otro lado, nosotros hemos estimado tasas de natalidad algo más elevadas, especialmente en el territorio cacereño, para 1752 y 1787 -cuadro 8-. Aunque el Censo de Floridablanca infravalore probablemente el número de habitantes, todo parece apuntar a que la tasa de natalidad en Extremadura no era inferior al 41 por 1.000 Iii a mediados ni a finales del siglo xvi11. Si no hemos empleado una tasa superior 
Producto de todas esas estimaciones son las cifras que aparecen en los cuadros 6 y 7 .

\section{CUADRO 6}

Evolución del nivel de los bautismos y de la población de Extremadura

(En números índice) *

\begin{tabular}{|c|c|c|c|c|c|c|}
\hline \multirow[b]{2}{*}{ Añor } & \multicolumn{3}{|c|}{ B A U T IS MOS } & \multicolumn{3}{|c|}{ РОВ В АС ION } \\
\hline & Caceres & Badajoz & $\begin{array}{l}\text { Extre- } \\
\text { madura }\end{array}$ & Cácere's & Badajoz & $\begin{array}{l}\text { Extro } \\
\text { madura }\end{array}$ \\
\hline$\ldots \ldots \ldots$ & 100,00 & 100,00 & 100,00 & 100,00 & 100,00 & 100,00 \\
\hline $1651 \ldots \ldots \ldots$ & 68,06 & 53,24 & 61,24 & 73,58 & 57,76 & 66,20 \\
\hline $1700 \ldots \ldots \ldots$ & 77,83 & 72,11 & 74,95 & 79,82 & 73,96 & 76,87 \\
\hline $1750 \ldots \ldots \ldots$ & 98,64 & 95,94 & 97,24 & 96,23 & 93,60 & 94,86 \\
\hline $1800 \ldots \ldots \ldots$ & 127.41 & 109,50 & 117,94 & 124,30 & 106,82 & 115,06 \\
\hline
\end{tabular}

* Se ha empleado como base 100 el nivel de los bautismos y la población de 1574.

Las nuevas estimaciones permiten matizar las primeras conclusiones extraídas de las series de bautismos y apreciar los contrastes entre las trayectorias demográficas de Cáceres y Badajoz:

1) En el último cuarto del siglo xvi y en la primera mitad del xvir la población extremeña disminuyó algo menos de lo que parece desprenderse

para 1800 ello se debe a que dicha fecha coincide con el final de un subperíodo alcista. El cociente medio entre bautismos y nupcias fue de 3,6 en 15 localidades cacereñas durante el siglo XVII, alcanzándose las cotas mínimas entre 1650 y 1669 , y no llegándose al 4 en la última década. Véase A. Rodríguez Grajera (1987), pp. 143 y 216 . Dicho cociente se mantuvo por encima de 4 durante el siglo xvill, con excepción de la segunda década del mismo, en seis pueblos de la Alta Extremadura, siendo el nivel de la segunda mitad de la centuria un 12,74 por 100 superior al de la primera. Véase M. A. Melón (1989), p. 52. Por otra parte, A. Rodríguez Grajera (1987), p. 129, ha estimado una tasa media de natalidad del 37,9 por 1.000 para 14 localidades cacereñas hacia 1646 . A la luz de todas estas informaciones, y teniendo en cuenta que el movimiento depresivo alcanzó su junto culminante en las dos décadas centrales del siglo xvII, nos ha parecido aconsejable utilizar tasas de natalidad del 37 y del 39 por 1.000 para 1651 y 1700 , respecti. vamente. Las pocas evidencias disponibles apuntan a que la fecundidad era más baja en la segunda mitad del siglo xvi que en el xvill. Véase A. Rodríguez Sánchez (1988), p. 289. Hemos optado por una tasa que consideramos máxima para 1574, fecha en la que se está produciendo la inflexión de la tendencia alcista, con el propósito de evitar la introducción de un sesgo que infle el movimiento depresivo. 


\section{CUADRO 7}

Tasas de crecimiento de la población extremeña (En porcentajes)

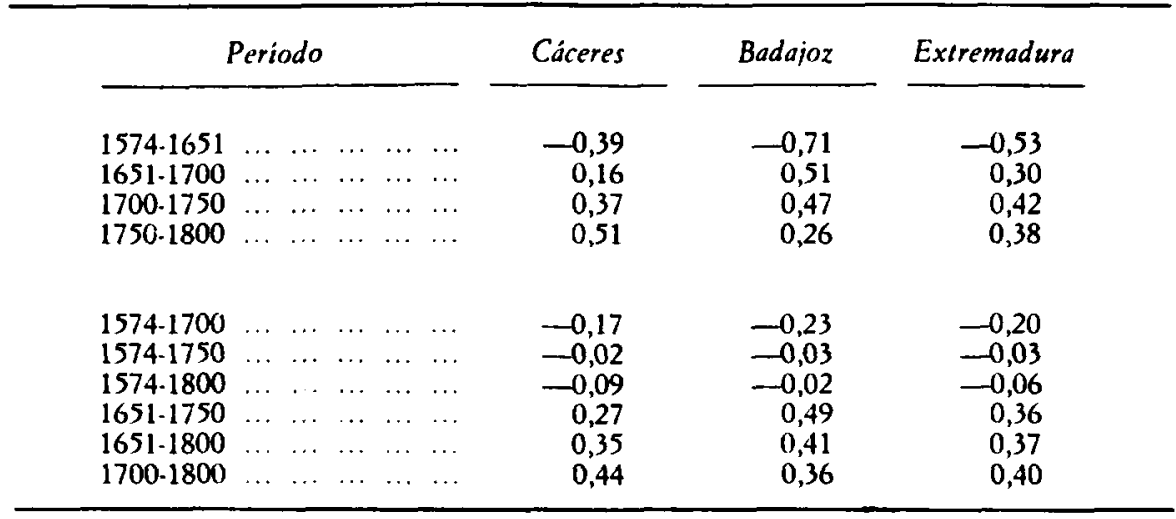

de la serie de bautismos de 37 localidades ${ }^{69}$. No obstante, la región debió perder, aproximadamente, la tercera parte de sus efectivos entre 1574 y 1651. Es indiscutible, por tanto, que la depresión fue prolongada e intensa.

2) Hacia mediados del siglo xviı la región aún no había recobrado el máximo demográfico del siglo xvi ${ }^{70}$. Como el descenso había ido bastante más rápido que la recuperación (cuadro 7 ), ésta tendría una dimensión temporal superior a la centuria.

3) El Setecientos, considerado aisladamente, no fue un período negativo para la demografía de la región, ya que la población extremeña creció a una tasa muy similar a la del conjunto de España ". Nuestro juicio debe variar al tener presente que, hacia 1700 , Extremadura ni siquiera había completado la recuperación de la tercera parte de los efectivos perdidos durante el movimiento depresivo. De ahí que el crecimiento «neto» del siglo xvilı

"Por dos razones: $1 .^{*}$ porque una parte, aunque pequeña, de la caída de los bautismos obedeció a la disminución de la tasa de natalidad; $2 .^{\text {A) }}$ porque la muestra está sesgada en favor de Badajoz, provincia en la que el hundimiento demográfico fue de mayor magnitud.

20 La entrada en juego de las tasas de natalidad estimadas suaviza algo el perfil del movimiento depresivo, pero también hace aún menos vigorosa la recuperación.

"El balance del siglo xvili que aquí presentamos es algo más optimista que el expuesto por E. Llopis, quien se había basado en los registros bautismales de 15 localidades, 5 pacenses y 10 cacereñas. Véase E. Llopis (1989), pp. 268-273. También nos parece que puede pecar por defecto la tasa de crecimiento estimada por M. A. Melón para el territorio cacereño entre 1752 y 1790 . Véase M. A. Melón (1989), pp. 38 y 43. 
fuera exiguo en la región, si bien ese atraso relativo en el aspecto demográfico sería subsanado, al menos en parte, durante el primer tercio del siglo xix.

4) La depresión fue de bastante mayor magnitud en Badajoz que en Cáceres, aunque allí durase una década menos (gráficos 3 y 4 ). En general, los movimientos de la población parecen ser más bruscos en la Baja que en la Alta Extremadura; ello pudo obedecer a la mayor versatilidad de los recur sos agrarios de la primera $y / o$ al menor grado de autorregulación demográfica.

5) Pese a que la recuperación fue más temprana e intensa en Badajoz que en Cáceres, el balance demográfico del período 1574-1750 seguía siendo ligeramente menos desfavorable para la Alta que para la Baja Extremadura.

6) En la segunda mitad del siglo xviu la tasa de crecimiento de Cáceres casi duplicó a la de Badajoz, lo que motivó que la primera tuviera hacia 1800 un 24,3 por 100 más habitantes que en 1574 , mientras que en la segunda el saldo positivo sólo alcanzase el 6,82 por 100. Durante el primer tercio del siglo xix la Baja Extremadura recuperaría parte del terreno perdido en relación a la Alta, pero fue después de 1835 cuando el mayor potencial de crecimiento demográfico de Badajoz se haria plenamente efectivo, hasta el punto de que en 1857 va concentraba el 57.27 por 100 de la población extremeña.

\section{V. ¿Sulen bien librudos los censos de 15\%1, 1752 y 1787 de los tests de fiabilidad?}

No hemos querido dejar de aprovechar la oportunidad de utilizar nuestras series de bautismos para poner a prueba la fiabilidad de los recuentos generales de población más usados en los estudios demográficos de los territorios de la Corona de Castilla durante el Antiguo Régimen: el Vecindario de 1591. el Catastro de 1752 y el Censo de Floridablanca. Además, algunas contradicciones entre los datos censales y los registros bautismales convirtieron nuestra inclinación inicial en necesidad imperiosa de acometer tal proyecto.

Según el Censo de 1591, Extremadura contaba entonces con 125.589 ve$\operatorname{cinos}^{n}$; el Censo de 1787 arroja la cifra de 423.492 habitantes. Suponiendo

"Al territorio de la Comunidad Autónoma de Extremadura pertenecen numerosos núcleos que no formaban parte, en 1591, de las provincias de Trujillo y León, de la Orden de Santiago: Berrocalejo, Bodon, El Gordo, Carrascalejo, Bohonal de Ibor, La Poveda, Puebla de Naciados, Talavera la Vieja, Torremenga, Alía, La Avellaneda, Castañar de Ibor, Garvín, Guadalupe, Iglesia de Lagar, Navalvillar de Ibor, Navatrasierra, Peraleda de San Román, Valdelacasa de Tajo, Villar del Pedroso, Abadía, Acebo, Ahigal, Aldeanueva del Camino, Aldehuela, Baños de Montemayor, El Bronco, Cachorrilla, Calzadilla, La Cañada, Casar de Palomero, Casas de Don Gómez, Casillas de Coria, Cerezo, Cilleros, Coria, Las Corzas, Descargamaria, Eljas, Garganta la Olla, La Garganta, Granadilla, La Granja, 
un coeficiente de 3,7 , que es poco probable que peque por exceso, la región habría albergado 464.679 habitantes en 1591. Quiere ello decir que la población extremeña habría descendido un 8,86 por 100 entre ambas fechas ${ }^{73}$. Sin embargo, en 1787, el nivel de los bautismos en las 37 localidades de la muestra era un 26,60 por 100 superior al de 1591 . Si la tasa de natalidad regional hubiese sido del 42 por 1.000 hacia $1787^{74}$, aquélla habría debido de ser de sólo el 30,23 por 1.000 hacia 1591 para hacer compatibles el crecimiento del nivel de los bautismos con el referido descenso de población. Es casi seguro que la tasa de natalidad era más elevada en 1787 que en 1591, pero no resulta verosímil, pese al movimiento contractivo que venía registrando la demografía extremeña desde 1575, que el diferencial rebasase el 10 por 1.000 y que dicha tasa sólo alcanzase el 30,23 por 1.000 en la última década del siglo $x_{1}{ }^{75}$. Al no resultar admisible una tasa de natalidad tan exigua, las importantes contradicciones entre los datos censales y los registros bautismales únicamente pueden explicarse por la sobrevaloración de los efec. tivos humanos del recuento de $1591^{76}$ y $/$ o por la infravaloración de los mismos del de $1787 \%$. La estimación de las tasas de natalidad en las fechas de los recuentos nus ayudará a corroborar la existencia de tales sesgos y el alcance de los mismos.

Para acceder al objetivo fijado se requiere previamente optar por un coeficiente habitantes/vecinos para 1591 y 1752. Esta cuestión resulta cada vez menos espinosa, ya que las opiniones de los especialistas se aproximan en esta

Guijo de Coria, Guijo de Granadilla, Hervás, Hoyos, Huélaga, Marchagaz, Mohedas, Morcillo, Palomero, Pasarón de la Vera, Pedroso de Acim, Perales del Puerto, Pescueza, Portaje, Puñoenrostro, Roblcdillo de Gata, San Martín de Trevejo, Santibáñez el Bajo, Torrejoncillo, Trevejo, Valverde del Fresno, Villamicl, Villanueva del Fresno, Villoria, Zarza de Granadilla, Bohonal de la Sierra, Fregenal de la Sierra, Higuera la Real, Castilblanco, Valdecaballeros, Olivenza y Táliga. Por ei contrario, Guadalcanal, Belalcázar, Fuente la Lancha, Hinojosa del Dique, Villanueva del Duque, Arroyomolinos de León y Cañaveral de León, que en 1591 pertenecían a la provincia de Trujillo o a la de León, de la Orden de Santiago, no forman parte de las actuales provincias de Cáceres y Badajoz.

"Si hubiéscmos empleado un coeficiente más alto, el descenso habría sido aún mayor.

" Resulta poco probable que la tasa de natalidad superase con claridad el 42 por 1.000 en el conjunto de la región.

"Para la estimación de la natalidad hemos empleado medias móviles de nueve años al objeto de intentar minimizar el impacto de las fuertes oscilaciones interanuales. De hecho, buscamos medir la natalidad en un entorno temporal, no en un año concreto.

it Son numerosos los trabajos yue han sostenido esta opinión, aun cuando la mayor parte de ellos se refería exclusivamente a núcleos urbanos. Véanse B. Bennassar (1967), pp. 162-170; F. Ruiz Martín (1966); F. Brumont (1978); J. I. Gutiérrez Nieto (1968), pp. 605-613. Sin embargo, $A$. Molinié-Bertrand (1975), pp. 125.138, sostiene que los datos de la provincia de Trujillo son bastante fiables.

"Descle hace años suele considerarse que las oscilaciones de este recuento varían entre el 5 y el 10 por 100 . Véanse F. Bustelo (1972) y V. Pérez Moreda (1988), p. 385. 
materia: cuando el marco espacial de una investigación lo constituye un territorio relativamente extenso $\longrightarrow$ una muestra amplia de localidades- del interior de la Corona de Castilla, el riesgo de cometer un grave error parece ser bastante reducido al emplear coeficientes comprendidos entre 3,7 y $4^{78}$. Por otro lado, utilizando los datos del Censo de Floridablanca y del Interrogatorio de la Real Audiencia de Extremadura de 1790, Miguel A. Melón Jiménez ha estimado un coeficiente de 3,84 para 78 núcleos cacereños ${ }^{79}$ Por tanto, la elección de aquél no nos ha planteado graves problemas, máxime si tenemos en cuenta que para intentar demostrar el sesgo alcista del Vecin. dario de 1591 estábamos obligados a movernos en los límites inferiores de la banda recomendada por los especialistas.

Una vez justificada la elección de los coeficientes, ya estamos en condiciones de comentar los resultados de las estimaciones. Habiendo empleado para 1591 un coeficiente de 3,7, consideramos poco verosimiles tasas de natalidad inferiores al 34 por 1.000. De acuerdo con esta hipótesis, el Vecindario de 1591 sobrevalora la población de cínco núcleos cacereños y de diez pacenses - cuadro 8-. Es decir, ese «mal» pudo afectar a cerca del 40 por 100 de las localidades de la muestra. Por otro lado, ese sesgo alcista no se concentró en núcleos de un determinado tamaño, aunque parece alcanzar mayores proporciones en la Baja Extremadura. En contrapartida a esas tasas de natalidad, poco verosímiles por su cortedad, el Vecindario de 1591 da la impresión de subestimar la población de sólo dos pueblos de la muestra, Membrío y Monterrubio de la Serena. Consiguientemente, el sesgo alcista del recuento no pudo, ni mucho menos, ser compensado por el de signo opuesto.

Resulta lógico que hacia 1590 la tasa de natalidad de las localidades cacereñas fuese algo superior a la de las pacenses, ya que el descenso de población estaba siendo más suave en aquéllas. Ahora bien, si se juega con la hipótesis de un coeficiente de 3,7 , resulta probable que la tasa de natalidad no fuese inferior al 38 por 1.000 en el conjunto regional $\rightarrow$ en el de los 37 pueblos de la muestra- ${ }^{80}$. Caso de ser acertada esta proposición, el Vecin-

" J. López-Salazar (1976), pp. 233-299; A. García Sanz (1978), p. 43; M. Martín Galán (1985), p. 610, y M. A. Melón (1989), p. 30. Resulta llamativa la coincidencia de los coeficientes medios de distintos territorios de las dos Castillas y Extremadura. Es cierto que la mayor parte de dichos coeficientes han sido estimados para la segunda mitad del siglo xvirI, pero los demógrafos parecen cada vez más convencidos de que los de la segunda mitad del Quinientos no pudieron ser muy diferentes de los del Setecientos. Aunque se trata de un núcleo urbano, no resulta intrascendente que el coeficiente de la ciudad de Cáceres en la segunda mitad del xvi sea muy similar al estimado para 78 núcleos de la Alta Extremadura a finales del siglo xviII. Véase A. Rodríguez Sánchez (1977), pp. 224-228.

M. A. Melón (1989), p. 30.

* Si se maneja un coeficiente algo mayor, ese límite establecido a la tasa de natalidad deberá reducirse. 


\section{CUADRO 8}

Tasas de natalidad estimadas

\begin{tabular}{|c|c|c|c|c|}
\hline & $1591 \%$ & $1591 \approx$ & $1752 \div *$ & 1787 \\
\hline \multicolumn{5}{|l|}{ Localidades de Cáceres } \\
\hline 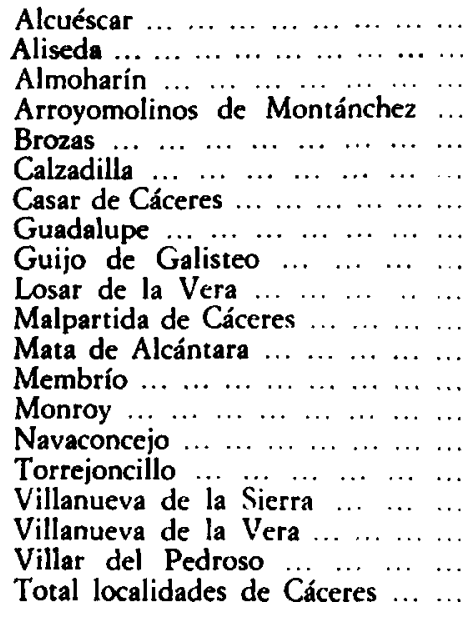 & $\begin{array}{l}37,29 \\
38,80 \\
40,95 \\
30,48 \\
36,30 \\
35,83 \\
31,47 \\
40,30 \\
30,35 \\
34,15 \\
37,06 \\
38,50 \\
51,86 \\
28,96 \\
37,07 \\
38,07 \\
24,20 \\
33,51 \\
34,85 \\
35,93\end{array}$ & $\begin{array}{l}38,61 \\
40,17 \\
42,39 \\
31,55 \\
37,57 \\
37,09 \\
32,58 \\
41,71 \\
31,42 \\
35,35 \\
38,36 \\
39,85 \\
53,68 \\
29,98 \\
38,37 \\
39,40 \\
25,05 \\
34,69 \\
36,07 \\
37,19\end{array}$ & $\begin{array}{r}39,33 \\
48,66 \\
40,33 \\
89,46 \\
37,72 \\
27,97 \\
47,02 \\
46,00 \\
37,47 \\
42,50 \\
48,65 \\
38,33 \\
33,25 \\
- \\
47,87 \\
117,68 \\
39,82 \\
116,49 \\
46,87\end{array}$ & $\begin{array}{l}41,56 \\
47,75 \\
39,81 \\
48,01 \\
43,37 \\
40,53 \\
50,05 \\
42,91 \\
35,11 \\
47,80 \\
58,10 \\
53,97 \\
42,11 \\
43,27 \\
50,22 \\
46,62 \\
42,75 \\
54,44 \\
40,22 \\
45,96\end{array}$ \\
\hline \multicolumn{5}{|l|}{ Localidades de Badajoz } \\
\hline 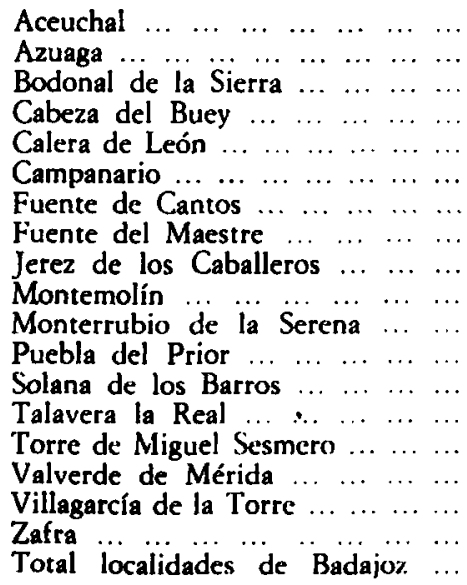 & $\begin{array}{l}30,46 \\
31,02 \\
33,40 \\
39,13 \\
23,45 \\
32,67 \\
31,91 \\
35,00 \\
37,09 \\
28,07 \\
56,45 \\
30,51 \\
27,74 \\
35,40 \\
25,16 \\
34,14 \\
30,10 \\
38,73 \\
33,99\end{array}$ & $\begin{array}{l}31,53 \\
32,11 \\
34,58 \\
40,50 \\
24,27 \\
33,82 \\
33,03 \\
36,23 \\
38,39 \\
29,06 \\
58,43 \\
31,58 \\
28,71 \\
36,65 \\
26,05 \\
35,34 \\
31,16 \\
40,10 \\
35,19\end{array}$ & $\begin{array}{c}41,14 \\
39,63 \\
- \\
41,05 \\
40,50 \\
41,61 \\
41,51 \\
39,47 \\
38,66 \\
43,27 \\
46,91 \\
40,97 \\
-\overline{52} \\
43,29 \\
34,48 \\
49,18 \\
38,13 \\
40,97\end{array}$ & $\begin{array}{l}47,96 \\
54,37 \\
44,48 \\
44,12 \\
47,50 \\
44,95 \\
49,10 \\
38,25 \\
41,22 \\
42,48 \\
42,70 \\
58,00 \\
32,57 \\
47,87 \\
48,75 \\
48,81 \\
45,20 \\
35,91 \\
43,76\end{array}$ \\
\hline
\end{tabular}

* Suponiendo un coeficiente habitantes/vecino de 3,83.

* Suponiendo un coeficiente habitantes/vecino de 3,7.

** Suponiendo un coeficiente habitantes/vecino de 3,84.

Fuentes: Las mismas del cuadro A.2 del Apéndice estadístico; Censo de Castilla de 1591. Vecindarios (1984); M.' Dolores Marcos González (1971), pp. 100-105; Censo de 1787 afloridablancas, tomo 2. Comunidades Autónomas de la Sub. meseta Sur (1987). 
dario de 1591 habría sesgado al alza la población de los núcleos de la muestra en algo más de un 5 por 100. Parece bastante probable que la cifra regional padezca una sobrevaloración no inferior a ese porcentaje.

En los dos recuentos del Setecientos sometidos a examen el problema que se plantea es el inverso, razón por la cual vamos a emplear un coeficiente algo más elevado a fin de probar el sesgo a la baja del Catastro de la Ensenada. De las 33 localidades para las que se ha estimado la tasa de natalidad hacia 1752, nueve arrojan cifras superiores al 47 por 1.000 . En todas ellas, cuando menos, existen indicios razonables de infravaloración del vecindario. En este caso, el problema se concentra en el territorio cacereño, dado que a él pertenecen siete de esas nueve localidades. En algunos núcleos, más que de sospechas, se dispone de plena certidumbre, resultando totalmente inverosímiles las tasas de Torrejoncillo, Villanueva de la Vera y Arroyomolinos de Montánchez - cuadro 8-. La tasa de natalidad estimada para 16 pueblos pacenses $(40,97$ por 1.000$)$ es perfectamente admisible, tanto por aproximarse a las cifras manejadas de modo habitual para la segunda mitad del siglo xvil como por la escasa dispersión de los datos locales con respecto a dicho valor ". No sucede lo mismo con la calculada para 17 localidades cacereñas, pues aunque éstas registraron un crecimiento mayor que las pacenses en la segunda mitad del siglo xviII -cuadro 7-, resulta prácticamente imposible que la tasa de natalidad fuese de casi el 47 por 1.000 en una porción bastante extensa del territorio provincial. Suponiendo que en esos 17 pueblos cacereños dicha tasa fuese del 43 por 1.000 , cota que probablemente no se alcanzaba, la infravaloración del Catastro de la Ensenada en la Alta Extremadura podría no ser inferior al 9 por 100. Como en Badajoz es posible que también existiese un pequeño saldo neto de ocultaciones, no parece descabellado afirmar que el Catastro de la Ensenada subestima el número de vecinos de la región en un porcentaje cercano al 5 por 100.

Las tasas de natalidad estimadas para 1787 también inducen a pensar que el Censo de Floridablanca infravalora la población extremeña. Resultan difícilmente inadmisibles las tasas provinciales del 45,96 y 43,76 por 1.000 para Cáceres y Badajoz, respectivamente. El número de habitantes de la primera creció al 0,51 por 100 en la segunda mitad del siglo xvili, pero resulta muy dudoso, habida cuenta del comportamiento de la mortalidad ${ }^{82}$, que esa expansión requiriese una tasa de natalidad de casi el 46 por 1.000 en el conjunto de la provincia. En Badajoz, donde la tendencia alcista de la población estaba siendo bastante menos intensa, parece muy poco probable que la tasa de

" En 12 de los 16 núcleos de la muestra la tasa de natalidad se situó entre el 38 $y$ el 44 por 1.000 .

"2 En ese entorno no se produjeron graves crisis de mortalidad. Véase $M$. A. Melón (1989), pp. 53.59 . 
natalidad superase el 42 por 1.000 . Por otro lado, descendiendo a las cifras locales, y aunque en éstas son aceptables valores algo más alejados de las medias generalmente empleadas ${ }^{83}$, también resulta significativo que en 16 pue. blos, ocho de cada provincia, la tasa de natalidad estimada superase el 47 por $1.000^{84}$. Quiere ello decir que los datos del Censo de Floridablanca pueden estar sesgados a la baja en el 40 por 100 de los núcleos de la región. Caso de que el número de habitantes de las localidades de la muestra fuera, en 1787, un 7 por 100 superior al registrado por el Censo de Floridablanca, la tasa de natalidad estimada para el conjunto de aquéllas todavía ascendería al 41,76 por 1.000 ; en consecuencia; resulta probable que la infravaloración del recuento de 1787 sea, en Extremadura, cercana al 7 por 100 .

En síntesis, los recuentos de 1591,1752 y 1787 no salen demasiado bien librados de los test de fiabilidad ${ }^{85}$ :

1) Aunque es probable que el coeficiente y la tasa de natalidad fuesen bastante bajos a finales del siglo xvi en el conjunto de la región, resulta improbable que ésta alcanzase los 125.000 vecinos en 1591 . El censo de esta fecha puede haber inflado su número en un porcentaje no inferior al 5 por 100 .

2) Las tasas de natalidad estimadas para los núcleos pacenses no cuestionan la fiabilidad de los datos demográficos del Catastro de la Ensenada. Sin embargo, no ocurre igual con las localidades cacereñas, en las que no puede admitirse una tasa próxima al 47 por 1.000 para 17 de ellas. El nivel de los registros bautismales apunta hacia una subestimación del vecindario de la Alta Extremadura cercana al 10 por 100.

3) El Censo de Floridablanca viene siendo considerado como el mejor recuento de la España del Antiguo Régimen. Los argumentos susceptibles de esgrimirse en su favor son evidentes: cubre todo el territorio nacional, obvia el engorroso problema del coeficiente y proporciona valiosas informaciones para .el estudio de las actividades profesionales y de la estructura por edades de la población. Aun así, en Extremadura, de acuerdo con los resultados de los test de fiabilidad a que lo hemos sometido, su exactitud no parece ser mayor que la del «Censo de los millones» o que la del Catastro

"M. Rodríguez Cancho (1989), p. 9, considera tasas verosímiles para la época las situadas entre el 35 y el 45 por 1.000 . Aquí hemos sido algo más permisivos y sólo hemos calificado de difícilmente admisibles las tasas locales superiores al 47 por 1.000 , ya que estamos intentando fundamentar la infravaloración del Censo de 1787.

"Sólo en Solana de los Barros, núcleo que habia registrado una impresionante depresión demográfica de la que no había conseguido recuperarse, la tasa de natalidad no alcanzaba el 35 por 1.000 .

"Las conclusiones provisionales aqui esbozadas deberán ser sometidas a examen mediante la utilización de un mayor número de series de bautismos y mediante la contrastación de los datos censales con los de los padrones. 
de la Ensenada. El Censo de Floridablanca probablemente infravalora el número de habitantes de la región en un porcentaje cercano al 7 por 100 .

De las tasas de natalidad estimadas no se deduce que las cifras globales de los recuentos sean disparatadas, pero sí se infiere que pueden cometerse errores de bulto si se pretende estudiar la evolución demográfica de Extremadura a partir de estos tres recuentos; el mayor problema no radica en sus inexactitudes, sino en que el primero presenta un sesgo de signo opuesto al de los dos restantes. Por tanto, si no se corrigen las cifras, el nivel de población de finales del xVI se sobrevalora y el de la segunda mitad del siglo xvirI se subestima. De ahí que hayamos cargado en exceso las tintas sobre el comportamiento negativo de la población extremeña. El balance demográfico del período $1570-1800$ es bastante pobre, pero, en contra de lo que algunos habíamos afirmado ${ }^{\circ 6}$, la región debía tener más habitantes en 1787 que en 1591.

Pese a haber efectuado estimaciones sobre el movimiento de la población y sobre los sesgos de los recuentos generales, no nos atrevemos a ofrecer cifras de habitantes para diferentes fechas porque, entre otros motivos, las 37 localidades de la muestra parecen tener un comportamiento demográfico ligeramente mejor que el del conjunto de los núcleos extremeños: aquéllas albergaban el 15,6 y el 17,47 por 100 de los efectivos humanos de la región en 1591 y 1787, respectivamente ${ }^{87}$. Es probable, por tanto, que el cuadro 6 haya suavizado la depresión y exagerado la intensidad de la recuperación. Es decir, las cifras de aquél deben ser consideradas como máximos.

E E. Llopis (1989), pp. 268-273.

3) Aunque las consideremos poco probables, ese fenómeno admite otras explicaciones: 1) en 1591 el coeficiente de los núcleos de la muestra era superior al del conjunto regional; 2) el sesgo alcista del Vecindario de 1991 fue de menor intensidad en las 37 regional; 2) el sesgo alcista del Vecindario de 1591 fue de menor intensidad en las 37 localidades de la muestra que en toda Extremadura y/o la subestimación del Censo de Floridablanca alcanzó cotas más reducidas en aquéllas que en éstas. 


\section{BIBLIOGRAFIA}

Bennassar, B. (1967): Valladolid au siècle d'Or. Une ville et sa campagne au XVle siècle. París.

Buıbao, L. M. (1983): «Exportación y comercialización de lanas de Castilla durante el siglo xviı, 1610-1720m, en El pasado bistórico de Castilla y Le'on. II. Edad Moderma. Burgos.

BRUMoNT, F (1978): “L'evolution de la population rurale durant le regne de Philippe II L'exemple du Nord-Ouest de la Vicille Castille», Mélanges de la Casa de Velázquez. t. XIV.

Bustelo, F. (1972): «La población española en la segunda mitad del siglo xvill». Moneda y Crédilo, núm. 123.

Cabrera, E., y Lora, G. (1984): “Datos sobre la población y la configuración jurisdiccional de Extremadura en el tránsito de la Edad Media a la Modernaw, Ifigea, núm. I. Córdoba

Censo de Castilla de 1591. Vecindarios (1984), INE, Madrid.

Censo de 1787 "Floridablanca». 2. Comunudades Autónomas de la Submeseta Sur (1987). Madrid.

Fspaña. Allas ' indices de sus tírminos municipales (1969). Madrid.

Garcia España, R., y Molinié-Birtrand. A. (1983): Censel de Casilla de 1591. Estudio analitico, Madrid.

(iarcía Pért\%, J., y Sánciht. Makkuro. l: (1984): «Extremadura a tines del siglo xvill y" comienzos del $\mathrm{x} 1 \mathrm{x}$ : conflictos campesinos, crisis agrarias $\mathrm{y}$ crisis de subsistencias $\mathrm{y}$ agobios fiscales". Norba, núm. 5. Cáceres.

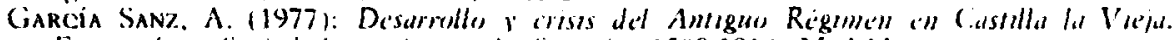
Econemmia y Sesciedad i'll tierras de Sigovia, 1500-1814. Madrid.

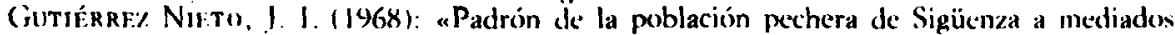
del siglo xv!». Anuaries de Historia Fionomica y Social, Madrid.

LE: Flem, J. P. (1972): aLas Cuentas de la Mesta, 1510-1709". Maneda y Creddites. núm. 121.

López-Salazar, I. (1976): “Fuolución demogrática de La Mancha en el siglo xvill". Hispania, núm. 133.

Li.opIS, E. (1982): "Las explotaciones trashumantes en el siglo xvill y primer tercio del xix: la cabaña del Monasterio de Guadalupe, 1709-1835», en G. ANEs (ed.), La economía española al final del Antiguo Régimen. I. Agriculiura, Madrid.

- (1985): "Algunas consideraciones acerca de la producción agraria castellana en los veinticinco últimos años del Antiguo Régimenm, en A. García Sanz y R. Garrabou (eds.), Histuria agraria de la España confemporanea. I. Cambio social y nuevas formas de propiedad. 1800-1850. Barcelona.

- (1989): «El agro extremeño en el Selecientos: crecimiento demográfico, "invasión mesteña" y conflictos socialesn, en listructuras agrarias y reformismo ilustrades en la España del siglo XVIII. Madrid.

Martín Galán, M. (1985): aNuevos datos sebre un viejo problema: el coeficiente de conversión de vecinos en habitantesm, Revista Internacional de Sociologia, $43,4$. Madrid.

Melón Jiménez, M. A. (1988): «Los desposeídos del campo extremeño. Arrendatarios, pegujaleros y jornaleros a finales del Antiguo Régimen», en Homenaje "Sebastián Gurcia Martinez, III, Valencia.

- (1989): Extremadura en al Antiguo Régimen. Econumia y Sociedad en tierras de Cáceres, 1700-1814. Salamanca.

Molinié-Bertrand, A. (1975): "Contribution à l'étude de la société rurale dans la province de Trujillo au xviè siecles, Mélange's $C h$. V. Aubrun, París.

NADAl, J. (1988): aLa población española durante los siglos xvi, xvil y xvul. Un ba. lance a escala regional», en V. Pérez MOREDA y D. S. Reher (eds.), Demografia bistórica en España, Madrid. 
Ptikez Moreda, V. (1980): Las crisis de mortalidad en la España interior (siglos XVI$X(X)$, Madrid.

- (1988): «La población española», en M. Artola (dir.). Enciclopedia de Historia de España. I. Economia, Sociedad, Madrid.

Rodríguez Cancho, M. (1981): La villa de Cáceres en el siglo XVIII. Demografia y Sociedad, Cáceres.

- (1985): aDefensa de la agricultura extremeña a finales del siglo xvili: quejas y protestas». Norba, núm. 6, Cáceres.

- 1989): «El Censo de Floridablanca (1787) en Extremadura. Análisis general y características demográficas" (en prensa).

Rodríguez Grajera, A. (1987): Población y estructura agraria en Cáceres durante el siglo XVII, tesis doctoral (en prensa), Cáceres.

- (1989): "Las crisis de mortalidad en la Alta Extremadura durante el siglo xvil". Revisla de la Asociación de Demografia Histónica, Madrid.

Rodríciutz Sánchez, A. (1977): Cáceres: Población y comportamientos demográficos en 'l siglo XVJ, Cáceres.

- (1979): «Guerra, miscria y corrupción en Extremadura: 1640-1668\%, en Estudios dedicados a Carlos Callejo, Cáceres.

- (1985): «Extremadura: la ticrra y los poderes», en Historia de Extremadura. III. Los liempos modernos, Badajoz.

- (1988): "La investigación en demografía histórica en Extremadura. Siglo xvi a 1850", en V. Pérez Moreda y D. S. Reher (eds.), Demogratia histórica en España, Madrid.

Ruiz Martin, F. (1966): «Un testimonio literario sobre las manufacturas de paños en Segovia en 1625", en Homenaje al profesor Alarcos, Valladolid.

YUN, B. (1985): «Producción agrícola en la Tierra de Campos y Segovia: contrastes, similitudes y problemas en torno a la agricultura castellana en los siglos XVI a XVIII" en III Congreso de Historia Ecomómica, Segovia.

Zaranoteta, F.: "Un vecindario de Almendralejo en 1665 , en II Jornadas de Meto. dología y Didáctica de la Historia, Cáceres. 


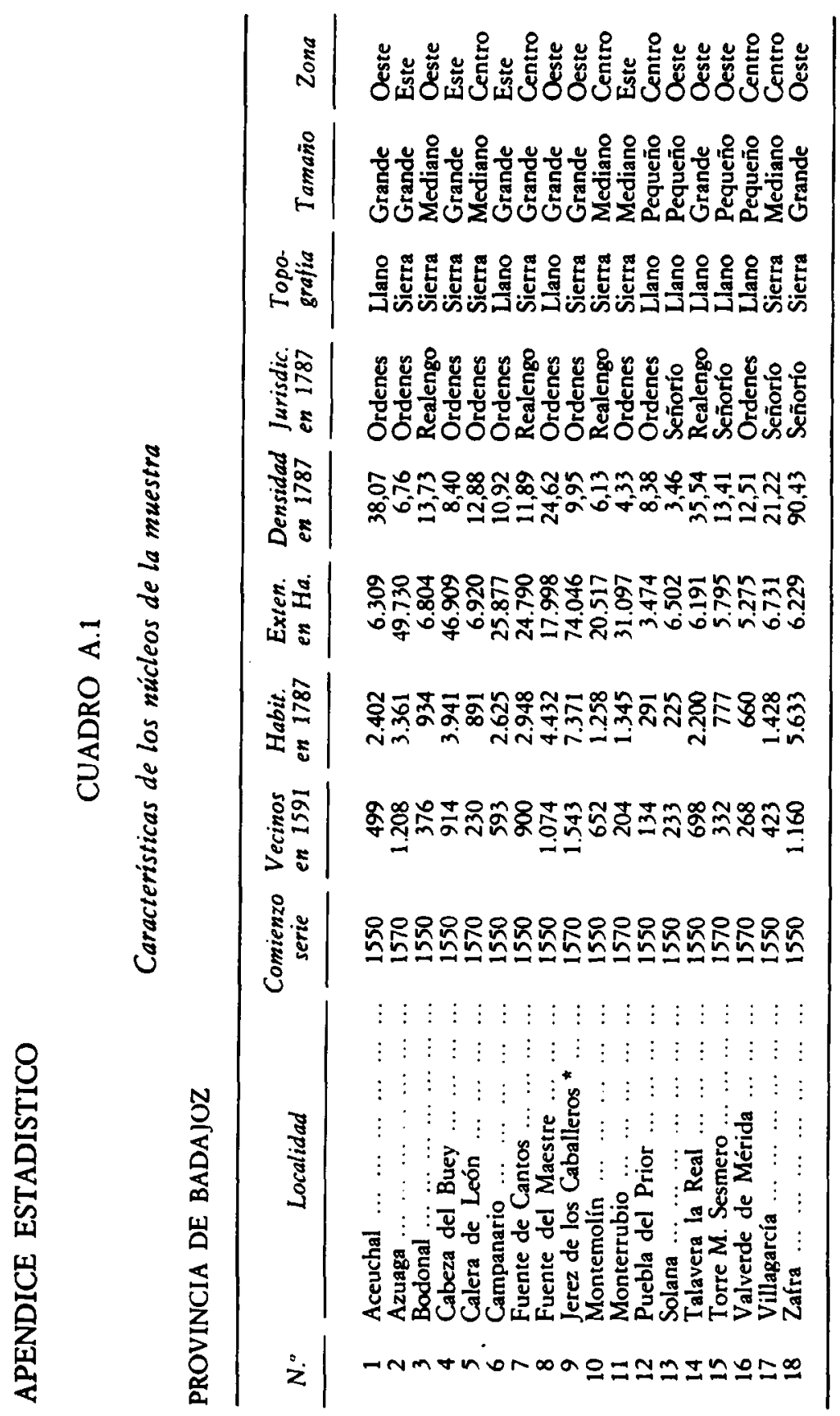




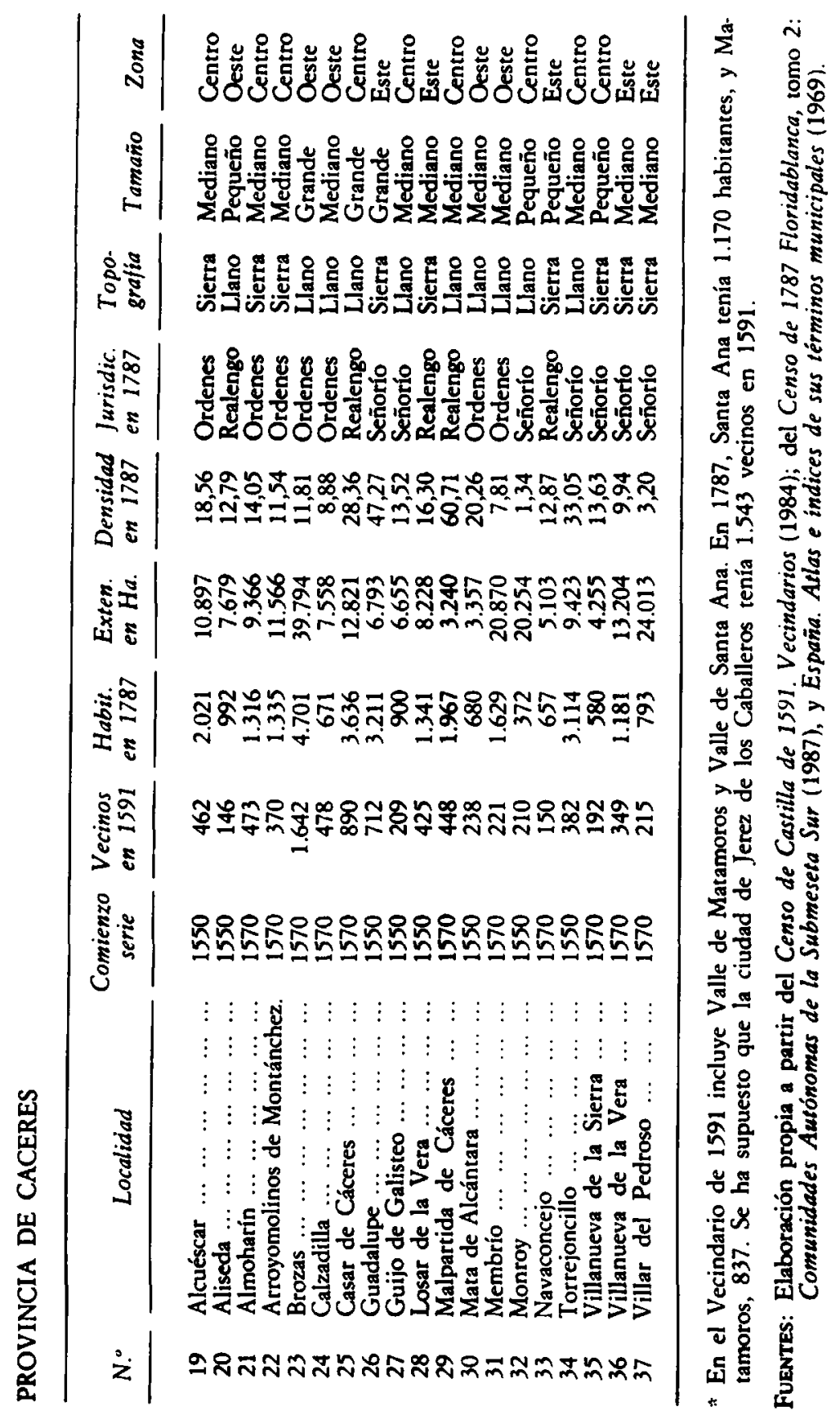




\section{CUADRO A.2}

Series de bautizados. Totales provinciales y regional (1550-1840)

\begin{tabular}{|c|c|c|c|c|}
\hline Años & $\begin{array}{l}20 \text { pueblos } \\
\text { Extremadura }\end{array}$ & $\begin{array}{l}37 \text { pueblos } \\
\text { Extremadura }\end{array}$ & $\begin{array}{l}18 \text { pueblos } \\
\text { Badajoz }\end{array}$ & $\begin{array}{l}19 \text { pueblos } \\
\text { Cáceres }\end{array}$ \\
\hline 1550 & 1.259 & - & - & - \\
\hline 1551 & 1.320 & - & - & - \\
\hline 1552 & 1.498 & - & - & - \\
\hline 1553 & 1.349 & - & - & - \\
\hline 1554 & 1.351 & - & - & - \\
\hline 1555 & 1.353 & - & - & - \\
\hline 1556 & 1.229 & - & - & - \\
\hline 1557 & 938 & - & - & - \\
\hline 1558 & 871 & - & - & - \\
\hline 1559 & 1.254 & - & - & - \\
\hline 1560 & 1.372 & - & - & - \\
\hline 1561 & 1.296 & - & - & - \\
\hline 1562 & 1.214 & - & - & - \\
\hline 1563 & 1.254 & - & - & - \\
\hline 1564 & 1.271 & - & - & - \\
\hline 1565 & 1.337 & - & - & - \\
\hline 1566 & 1.511 & - & - & - \\
\hline 1567 & 1.514 & - & - & - \\
\hline 1568 & 1.466 & - & - & - \\
\hline 1569 & 1.383 & - & - & - \\
\hline 1570 & 1.488 & 2.819 & 1.607 & 1.212 \\
\hline 1571 & 1.463 & 2.637 & 1.597 & 1.090 \\
\hline 1572 & 1.480 & 2.909 & 1.710 & 1.199 \\
\hline 1573 & 1.588 & 3.094 & 1.825 & 1.269 \\
\hline 1574 & 1.576 & 2.983 & 1.760 & 1.223 \\
\hline 1575 & 1.626 & 3.156 & 1.863 & 1.293 \\
\hline 1576 & 1.605 & 3.049 & 1.831 & 1.218 \\
\hline 1577 & 1.431 & 2.809 & 1.682 & 1.127 \\
\hline 1578 & 1.349 & 2.759 & 1.622 & 1.137 \\
\hline 1579 & 1.325 & 2.654 & 1.523 & 1.131 \\
\hline 1580 & 1.163 & 2.346 & 1.287 & 1.059 \\
\hline 1581 & 1.224 & 2.416 & 1.387 & 1.029 \\
\hline 1582 & 1.424 & 2.646 & 1.524 & 1.122 \\
\hline 1583 & 1.128 & 2.133 & 1.281 & 852 \\
\hline 1584 & 1.452 & 2.690 & 1.569 & 1.121 \\
\hline 1585 & 1.587 & 2.888 & 1.710 & 1.178 \\
\hline 1586 & 1.422 & 2.563 & 1.491 & 1.072 \\
\hline 1587 & 1.688 & 3.004 & 1.779 & 1.225 \\
\hline 1588 & 1.548 & 2.971 & 1.718 & 1.253 \\
\hline 1589 & 1.401 & 2.612 & 1.521 & 1.091 \\
\hline 1590 & 1.217 & 2.434 & 1.335 & 1.099 \\
\hline 1591 & 1.232 & 2.406 & 1.318 & 1.088 \\
\hline 1592 & 1.358 & 2.573 & 1.475 & 1.098 \\
\hline 1593 & 1.300 & 2.451 & 1.367 & 1.084 \\
\hline 1594 & 1.260 & 2.473 & 1.351 & 1.122 \\
\hline 1595 & 1.383 & 2.586 & 1.474 & 1.112 \\
\hline 1596 & 1.325 & 2.584 & 1.514 & 1.070 \\
\hline
\end{tabular}




\section{CUADRO A.2 (Continuación)}

Series de bautizados. Totales provinciales y regional (1550-1840)

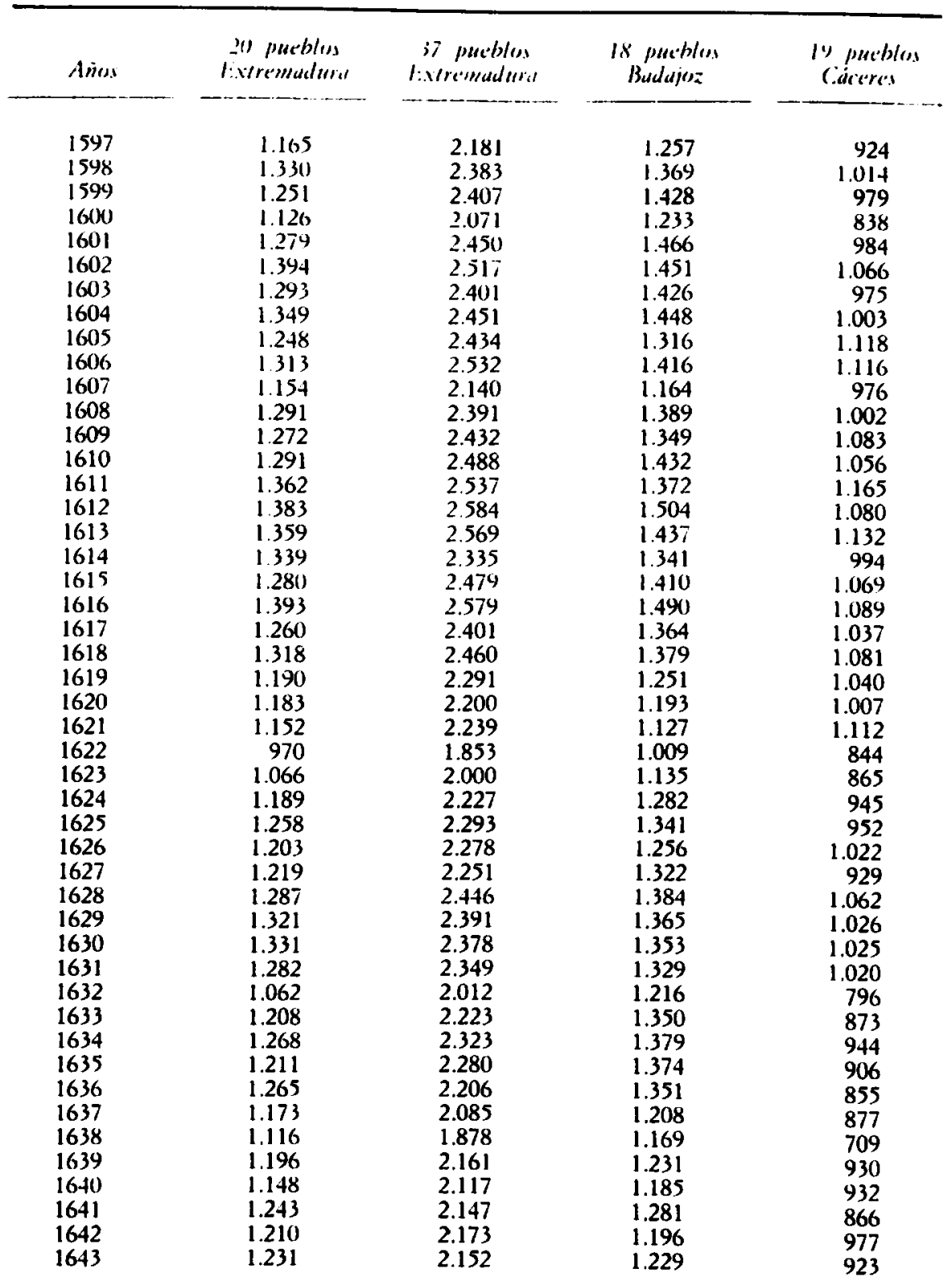




\section{CUADRO A.2 (Continuación)}

Series de bautizados. Totales provinciales y regional (1550-1840)

\begin{tabular}{|c|c|c|c|c|}
\hline$A \tilde{n} O S$ & $\begin{array}{l}20 \text { pueblos } \\
\text { Extremadurd }\end{array}$ & $\begin{array}{l}37 \text { pueblos } \\
\text { Extremadura }\end{array}$ & $\begin{array}{c}18 \text { pueblos } \\
\text { Badajoz }\end{array}$ & $\begin{array}{l}19 \text { pueblos } \\
\text { Cáceres }\end{array}$ \\
\hline $\begin{array}{l}1644 \\
1645 \\
1646 \\
1647 \\
1648 \\
1649 \\
1650 \\
1651 \\
1652 \\
1653 \\
1654 \\
1655 \\
1656 \\
1657 \\
1658 \\
1659 \\
1660 \\
1661 \\
1662 \\
1663 \\
1664 \\
1665 \\
1666 \\
1667 \\
1668 \\
1669 \\
1670 \\
1671 \\
1672 \\
1673 \\
1674 \\
1675 \\
1676 \\
1677 \\
1678 \\
1679 \\
1680 \\
1681 \\
1682 \\
1683 \\
1684 \\
1685 \\
1686 \\
1687 \\
1688 \\
1689 \\
1690\end{array}$ & $\begin{array}{r}1.163 \\
1.055 \\
1.155 \\
1.106 \\
995 \\
1.079 \\
992 \\
879 \\
932 \\
1.001 \\
1.044 \\
1.029 \\
1.105 \\
1.131 \\
1.087 \\
981 \\
1.071 \\
1.129 \\
1.176 \\
1.126 \\
1.232 \\
1.373 \\
1.237 \\
1.102 \\
1.104 \\
1.140 \\
1.195 \\
1.283 \\
1.243 \\
1.234 \\
1.305 \\
1.262 \\
1.290 \\
1.281 \\
1.282 \\
1.174 \\
1.302 \\
1.189 \\
1.231 \\
1.243 \\
1.035 \\
861 \\
1.032 \\
1.050 \\
1.024 \\
1.161 \\
1.234\end{array}$ & $\begin{array}{l}2.127 \\
1.917 \\
2.016 \\
1.963 \\
1.808 \\
1.789 \\
1.760 \\
1.550 \\
1.620 \\
1.811 \\
1.816 \\
1.846 \\
2.012 \\
1.969 \\
1.935 \\
1.737 \\
1.872 \\
1.953 \\
1.878 \\
1.892 \\
2.031 \\
2.222 \\
2.025 \\
1.876 \\
1.892 \\
2.009 \\
2.017 \\
2.196 \\
2.159 \\
2.095 \\
2.259 \\
2.161 \\
2.209 \\
2.205 \\
2.189 \\
2.037 \\
2.227 \\
2.051 \\
2.145 \\
2.094 \\
1.865 \\
1.605 \\
1.797 \\
1.862 \\
1.805 \\
2.002 \\
2.119\end{array}$ & $\begin{array}{r}1.212 \\
1.075 \\
1.125 \\
1.074 \\
930 \\
980 \\
919 \\
854 \\
877 \\
971 \\
1.000 \\
1.036 \\
1.093 \\
1.132 \\
1.081 \\
960 \\
1.090 \\
1.126 \\
1.201 \\
1.136 \\
1.248 \\
1.373 \\
1.213 \\
1.119 \\
1.091 \\
1.210 \\
1.211 \\
1.300 \\
1.267 \\
1.203 \\
1.345 \\
1.264 \\
1.315 \\
1.279 \\
1.283 \\
1.226 \\
1.316 \\
1.195 \\
1.236 \\
1.241 \\
1.004 \\
938 \\
1.058 \\
1.088 \\
1.042 \\
1.169 \\
1.217\end{array}$ & $\begin{array}{l}915 \\
842 \\
891 \\
889 \\
878 \\
809 \\
841 \\
696 \\
743 \\
840 \\
816 \\
810 \\
919 \\
837 \\
854 \\
777 \\
782 \\
827 \\
677 \\
756 \\
783 \\
849 \\
612 \\
757 \\
801 \\
799 \\
806 \\
896 \\
892 \\
892 \\
914 \\
897 \\
894 \\
926 \\
906 \\
811 \\
911 \\
856 \\
909 \\
853 \\
861 \\
667 \\
739 \\
774 \\
763 \\
833 \\
902\end{array}$ \\
\hline
\end{tabular}




\section{CUADRO A.2 (Continuación)}

Series de bautizados. Totales provinciales y regional (1550-1840)

\begin{tabular}{|c|c|c|c|c|}
\hline$A \tilde{n} o s$ & $\begin{array}{l}20 \text { pueblos } \\
\text { Extremadura }\end{array}$ & $\begin{array}{l}37 \text { pueblos } \\
\text { Extremadura }\end{array}$ & $\begin{array}{l}18 \text { pueblos } \\
\text { Badajoz }\end{array}$ & $\begin{array}{l}19 \text { pueblos } \\
\text { Cáceres }\end{array}$ \\
\hline $\begin{array}{l}1691 \\
1692 \\
1693 \\
1694 \\
1695 \\
1696 \\
1697 \\
1698 \\
1699 \\
1700 \\
1701 \\
1702 \\
1703 \\
1704 \\
1705 \\
1706 \\
1707 \\
1708 \\
1709 \\
1710 \\
1711 \\
1712 \\
1713 \\
1714 \\
1715 \\
1716 \\
1717 \\
1718 \\
1719 \\
1720 \\
1721 \\
1722 \\
1723 \\
1724 \\
1725 \\
1726 \\
1727 \\
1728 \\
1729 \\
1730 \\
1731 \\
1732 \\
1733 \\
1734 \\
1735 \\
1736 \\
1737\end{array}$ & $\begin{array}{l}1.219 \\
1.182 \\
1.127 \\
1.195 \\
1.218 \\
1.210 \\
1.183 \\
1.283 \\
1.277 \\
1.198 \\
1.302 \\
1.363 \\
1.352 \\
1.334 \\
1.399 \\
1.449 \\
1.405 \\
1.148 \\
1.124 \\
1.206 \\
1.325 \\
1.175 \\
1.227 \\
1.353 \\
1.319 \\
1.328 \\
1.385 \\
1.377 \\
1.283 \\
1.453 \\
1.422 \\
1.490 \\
1.407 \\
1.351 \\
1.406 \\
1.607 \\
1.435 \\
1.564 \\
1.612 \\
1.528 \\
1.566 \\
1.587 \\
1.580 \\
1.634 \\
1.226 \\
1.340 \\
1.305\end{array}$ & $\begin{array}{l}2.091 \\
2.070 \\
2.015 \\
2.013 \\
2.088 \\
2.126 \\
2.017 \\
2.176 \\
2.242 \\
2.092 \\
2.191 \\
2.418 \\
2.326 \\
2.387 \\
2.329 \\
2.491 \\
2.466 \\
2.037 \\
1.985 \\
2.059 \\
2.186 \\
1.993 \\
2.049 \\
2.251 \\
2.239 \\
2.300 \\
2.434 \\
2.429 \\
2.309 \\
2.570 \\
2.433 \\
2.555 \\
2.447 \\
2.326 \\
2.447 \\
2.738 \\
2.524 \\
2.767 \\
2.849 \\
2.611 \\
2.629 \\
2.763 \\
2.730 \\
2.858 \\
2.246 \\
2.392 \\
2.318\end{array}$ & $\begin{array}{l}1.224 \\
1.190 \\
1.148 \\
1.188 \\
1.283 \\
1.242 \\
1.225 \\
1.255 \\
1.275 \\
1.231 \\
1.282 \\
1.395 \\
1.368 \\
1.401 \\
1.384 \\
1.484 \\
1.454 \\
1.232 \\
1.223 \\
1.231 \\
1.318 \\
1.234 \\
1.285 \\
1.372 \\
1.345 \\
1.379 \\
1.466 \\
1.443 \\
1.402 \\
1.509 \\
1.472 \\
1.478 \\
1.431 \\
1.382 \\
1.473 \\
1.643 \\
1.500 \\
1.681 \\
1.685 \\
1.534 \\
1.595 \\
1.639 \\
1.637 \\
1.773 \\
1.317 \\
1.392 \\
1.313\end{array}$ & $\begin{array}{r}867 \\
880 \\
867 \\
825 \\
805 \\
884 \\
792 \\
921 \\
967 \\
861 \\
909 \\
1.023 \\
958 \\
986 \\
945 \\
1.007 \\
1.012 \\
805 \\
762 \\
828 \\
868 \\
759 \\
764 \\
879 \\
894 \\
921 \\
968 \\
986 \\
907 \\
1.061 \\
961 \\
1.077 \\
1.016 \\
944 \\
974 \\
1.095 \\
1.024 \\
1.086 \\
1.164 \\
1.077 \\
1.034 \\
1.124 \\
1.093 \\
1.085 \\
929 \\
1.000 \\
1.005\end{array}$ \\
\hline
\end{tabular}




\section{CUADRO A.2 (Continuación)}

Series de bautizados. Totales provinciales y regional (1550-1840)

\begin{tabular}{|c|c|c|c|c|}
\hline Años & $\begin{array}{l}20 \text { pueblos } \\
\text { Exiremadura }\end{array}$ & $\begin{array}{l}37 \text { pueblas } \\
\text { Exiremadura }\end{array}$ & $\begin{array}{c}18 \text { pueblos } \\
\text { Badajoz }\end{array}$ & $\begin{array}{l}19 \text { pueblos } \\
\text { Cáceres }\end{array}$ \\
\hline $\begin{array}{l}1738 \\
1739 \\
1740 \\
1741 \\
1742 \\
1743 \\
1744 \\
1745 \\
1746 \\
1747 \\
1748 \\
1749 \\
1750 \\
1751 \\
1752 \\
1753 \\
1754 \\
1755 \\
1756 \\
1757 \\
1758 \\
1759 \\
1760 \\
1761 \\
1762 \\
1763 \\
1764 \\
1765 \\
1766 \\
1767 \\
1768 \\
1769 \\
1770 \\
1771 \\
1772 \\
1773 \\
1774 \\
1775 \\
1776 \\
1777 \\
1778 \\
1779 \\
1780 \\
1781 \\
1782 \\
1783 \\
1784\end{array}$ & $\begin{array}{l}1.040 \\
1.215 \\
1.337 \\
1.244 \\
1.374 \\
1.570 \\
1.534 \\
1.516 \\
1.481 \\
1.661 \\
1.562 \\
1.593 \\
1.767 \\
1.530 \\
1.668 \\
1.721 \\
1.241 \\
1.324 \\
1.725 \\
1.609 \\
1.611 \\
1.741 \\
1.541 \\
1.652 \\
1.700 \\
1.567 \\
1.781 \\
1.567 \\
1.494 \\
1.566 \\
1.565 \\
1.563 \\
1.501 \\
1.507 \\
1.582 \\
1.665 \\
1.562 \\
1.786 \\
1.690 \\
1.814 \\
1.817 \\
1.826 \\
1.620 \\
1.577 \\
1.633 \\
1.782 \\
1.859\end{array}$ & $\begin{array}{l}1.944 \\
2.258 \\
2.395 \\
2.294 \\
2.426 \\
2.790 \\
2.758 \\
2.733 \\
2.750 \\
2.877 \\
2.818 \\
2.806 \\
3.150 \\
2.766 \\
2.960 \\
3.077 \\
2.314 \\
2.463 \\
3.091 \\
3.062 \\
2.998 \\
3.226 \\
2.950 \\
3.010 \\
3.098 \\
2.822 \\
3.258 \\
2.846 \\
2.763 \\
2.872 \\
2.801 \\
2.849 \\
2.715 \\
2.821 \\
2.922 \\
2.971 \\
2.845 \\
3.236 \\
3.087 \\
3.333 \\
3.249 \\
3.280 \\
2.921 \\
3.2839 \\
3.432\end{array}$ & $\begin{array}{l}1.083 \\
1.273 \\
1.363 \\
1.328 \\
1.431 \\
1.631 \\
1.583 \\
1.546 \\
1.562 \\
1.694 \\
1.671 \\
1.639 \\
1.868 \\
1.560 \\
1.716 \\
1.848 \\
1.304 \\
1.397 \\
1.742 \\
1.699 \\
1.690 \\
1.800 \\
1.625 \\
1.773 \\
1.842 \\
1.704 \\
1.847 \\
1.696 \\
1.658 \\
1.684 \\
1.609 \\
1.652 \\
1.571 \\
1.607 \\
1.651 \\
1.690 \\
1.605 \\
1.836 \\
1.735 \\
1.887 \\
1.823 \\
1.876 \\
1.699 \\
1.655 \\
1.725 \\
1.870 \\
1.946\end{array}$ & $\begin{array}{r}861 \\
985 \\
1.032 \\
966 \\
995 \\
1.159 \\
1.175 \\
1.187 \\
1.188 \\
1.183 \\
1.147 \\
1.167 \\
1.282 \\
1.206 \\
1.244 \\
1.229 \\
1.010 \\
1.066 \\
1.349 \\
1.363 \\
1.308 \\
1.426 \\
1.325 \\
1.237 \\
1.256 \\
1.118 \\
1.411 \\
1.150 \\
1.105 \\
1.188 \\
1.192 \\
1.197 \\
1.144 \\
1.214 \\
1.271 \\
1.281 \\
1.240 \\
1.400 \\
1.352 \\
1.446 \\
1.426 \\
1.404 \\
1.222 \\
1.284 \\
1.211 \\
1.419 \\
1.486\end{array}$ \\
\hline
\end{tabular}




\section{CUADRO A.2 (Continuación)}

Series de bautizados. Totales provinciales y regional (1550-1840)

\begin{tabular}{|c|c|c|c|c|}
\hline Añoss & $\begin{array}{l}20 \text { pueblos } \\
\text { l:xtremadura }\end{array}$ & $\begin{array}{c}37 \text { pueblos } \\
\text { i:xercmadura }\end{array}$ & $\begin{array}{c}18 \text { pueblos } \\
\text { Badajoz }\end{array}$ & $\begin{array}{l}19 \text { pueblos } \\
\text { Cáceres }\end{array}$ \\
\hline 1785 & 1.805 & 3.335 & 1.917 & 1.418 \\
\hline 1786 & 1.732 & 3.211 & 1.832 & 1.379 \\
\hline 1787 & 1.620 & 3.100 & 1.685 & 1.415 \\
\hline 1788 & 1.783 & 3.327 & 1.920 & 1.407 \\
\hline 1789 & 1.797 & 3.235 & 1.846 & 1.389 \\
\hline 1790 & 1.791 & 3.324 & 1.877 & 1.447 \\
\hline 1791 & 1.899 & 3.513 & 2.013 & 1.500 \\
\hline 1792 & 1.924 & 3.488 & 2.046 & 1.442 \\
\hline 1793 & 1.906 & 3.466 & 1.963 & 1.503 \\
\hline 1794 & 1.667 & 3.215 & 1.776 & 1.439 \\
\hline 1795 & $1.67 i$ & 3.349 & 1.825 & 1.524 \\
\hline 1796 & 1.926 & 3.493 & 1.990 & 1.503 \\
\hline 1797 & 1.709 & 3.264 & 1.807 & 1.457 \\
\hline 1798 & 1.873 & 3.502 & 1.934 & 1.568 \\
\hline 1799 & 1.759 & 3.210 & 1.866 & 1.344 \\
\hline 1800 & 1.843 & 3.499 & 1.981 & 1.518 \\
\hline 1801 & 1.970 & 3.519 & 2.014 & 1.505 \\
\hline 1802 & 1.856 & 3.569 & 1.938 & 1.631 \\
\hline 1803 & 1.930 & 3.578 & 1.922 & 1.656 \\
\hline 1804 & 1.948 & 3.625 & 2.006 & 1.619 \\
\hline 1805 & 1.453 & 2.652 & 1.542 & 1.110 \\
\hline 1806 & 1.596 & 2.823 & 1.588 & 1.235 \\
\hline 1807 & 1.791 & 3.148 & 1.841 & 1.307 \\
\hline 1808 & 1.786 & 3.224 & 1.826 & 1.398 \\
\hline 1809 & 1.890 & 3.346 & 1.901 & 1.445 \\
\hline 1810 & 1.665 & 3.087 & 1.721 & 1.366 \\
\hline 1811 & 1.904 & 3.327 & 1.759 & 1.568 \\
\hline 1812 & 1.495 & 2.768 & 1.591 & 1.177 \\
\hline 1813 & 1.564 & 2.832 & 1.630 & 1.202 \\
\hline 1814 & 1.849 & 3.350 & 1.846 & 1.504 \\
\hline 1815 & 1.824 & 3.396 & 1.832 & 1.564 \\
\hline 1816 & 2.096 & 3.765 & 2.139 & 1.626 \\
\hline 1817 & 2.149 & 3.911 & 2.151 & 1.760 \\
\hline 1818 & 2.329 & 4.137 & 2.318 & 1.819 \\
\hline 1819 & 2.228 & 4.050 & 2.324 & 1.726 \\
\hline 1820 & 2.221 & 4.086 & 2.302 & 1.784 \\
\hline 1821 & 2.546 & 4.640 & 2.621 & 2.019 \\
\hline 1822 & 2.397 & 4.357 & 2.470 & 1.887 \\
\hline 1823 & 2.438 & 4.410 & 2.568 & 1.842 \\
\hline 1824 & 2.627 & 4.766 & 2.792 & 1.974 \\
\hline 1825 & 2.494 & 4.522 & 2.574 & 1.948 \\
\hline 1826 & 2.489 & 4.605 & 2.699 & 1.906 \\
\hline 1827 & 2.569 & 4.544 & 2.752 & 1.792 \\
\hline 1828 & 2.542 & 4.574 & 2.646 & 1.928 \\
\hline 1829 & 2.458 & 4.492 & 2.582 & 1.910 \\
\hline 1830 & 2.305 & 4.171 & 2.455 & 1.716 \\
\hline 1831 & 2.211 & 4.027 & 2.315 & 1.712 \\
\hline
\end{tabular}




\section{CUADRO A.2 (Continuación)}

Series de bautizados. Totales provinciales y regional (1550-1840)

\begin{tabular}{|c|c|c|c|c|}
\hline Años & $\begin{array}{l}20 \text { pueblos } \\
\text { Extremadura }\end{array}$ & $\begin{array}{l}37 \text { pueblos } \\
\text { Extremadura }\end{array}$ & $\begin{array}{c}18 \text { pueblos } \\
\text { Badajoz }\end{array}$ & $\begin{array}{l}19 \text { pueblos } \\
\text { Cáceres }\end{array}$ \\
\hline $\begin{array}{l}1832 \\
1833 \\
1834 \\
1835 \\
1836 \\
1837 \\
1838 \\
1839 \\
1840\end{array}$ & $\begin{array}{l}1.959 \\
2.119 \\
2.096 \\
1.922 \\
1.916 \\
2.230 \\
2.038 \\
2.194 \\
2.219\end{array}$ & $\begin{array}{l}3.667 \\
3.864 \\
3.849 \\
3.582 \\
3.589 \\
4.206 \\
3.813 \\
4.131 \\
4.103\end{array}$ & $\begin{array}{l}2.066 \\
2.319 \\
2.261 \\
1.951 \\
1.955 \\
2.451 \\
2.111 \\
2.352 \\
2.273\end{array}$ & $\begin{array}{l}1.601 \\
1.545 \\
1.588 \\
1.631 \\
1.634 \\
1.755 \\
1.702 \\
1.779 \\
1.830\end{array}$ \\
\hline
\end{tabular}

Fuentes: A. P. de S. Pedro Apóstol. Aceuchal. Libros de Bautismo; A. P. de Ntra. Sra. de la Consolación. Azuaga. Libros de Bautismo; A. P. de San Blas. Bodonal de la Sierra. Libros de Bautismo; A. P. de Ntra. Sra. de la Armentera. Cabeza del Buey. Libros de Bautismo; A. P. de Santiago. Calera de León. Libros de Bautismo; A. P. de Ntra. Sra de la Asunción. Campanario. Libros de Bautismo; A. P. de Nrra. Sra. de la Granada. Fuente de Cantos, Libros de Bautismo; A. P. de Ntra. Sra. de la Candelaria. Fuente del Maestre. Libros de Bautismo; A. P. de S. Bartolomé. Jerez de los Caballeros. Libros de Bautismo; A. P. de S. Miguel. Jerez de los Caballeros. Libros de bautismo; A. P. de Santa Catalina. Jerez de los Caballeros. Libros de Bautismo; A. P. de Santa María. Jerez de los Caballeros. Libros de Bautismo; A. P. de la Purísima Concepción. Montemolín. Libros de Bautismo; A. P. de Ntra. Sra de la Consolación. Monterrubio. Libros de Bautismo; A. P. de S. Esteban. Puebla del Prior. Libros de Bautismo; A. P. de Santa María Magdalena. Solana de los Barros. Libros de Bautismo; A. P. de Santa María de Gracia. Talavera la Real. Libros de Bautismo; A. P. de Ntra. Sra. de la Candelaria. Torre de Miguel Sesmero. Libros de Bautismo; A. P. de Santa Marina. Valverde de Mérida. Libros de Bautismo; A. P. de Ntra. Sra. de Araceli. Villagarcía de la Torre. Libros de Bautismo; A. P. de Nira. Sra. de la Candelaria. Zafra. Libros de Bautismo; A. P. de Nira. Sra. de la Asunción. Alcuéscar. Libros de Bautismo"; A. P. de Ntra. Sra. de la Asunción. Aliseda. Libros de Bautismo *; A. P. del Salvador. Almoharín. Libros de Bautismo *; A. P. de Ntra. Sra. de la Consolación. Arroyomolinos. Libros de Bautismo *; A. P. de los Santos Mártires. Brozas. Libros de Bautismo *; A. P. de Santa María. Brozas. Libros de Bautismo *; A. P. de Ntra. Sra. de la Consolación. Calzadilla. Libros de Bautismo *; A. P. de la Asunción. Casar de Cáceres. Libros de Bautismo "; Archivo del Monasterio de Guadalupe. Códices. Libros de Bautismo; A. P. de S. Pedro. Guijo de Galisteo. Libros de Bautismo *; A. P. de Santiago Apóstol. Losar de la Vera. Libros de Bautismo; A. P. de la Asunción. Malpartida de Cáceres. Libros de Bautismo*; A. P. de Ntra. Sra. de Gracia. Mata de Alcántara. Libros de Bautismo "; A. P. de Ntra. Sra. de Gracia. Membrío. Libros de Bautismo *; A. P. de Santa Catalina. Monroy. Libros de Bautismo; A. P. de Santa María de la Asunción. Navaconcejo. Libros de Bautismo; A. P. de S. Andrés. Torrejoncillo. Libros de Bautismo *; A. P. de la Asunción. Villanueva de la Sierra. Libros de Bautismo *; A. P. de la Inmaculada Concepción. Villanueva de la Vera. Libros de Bautismo; A. P. de S. Pedro Apóstol. Villar del Pedroso. Libros de Bautismo.

A. P. = Archivo Parroquial.

* Depositados en el Archivo Diocesano de Coria-Cáceres. Cáceres. 